\title{
LOS METATHERIA SUDAMERICANOS DE COMIENZOS DEL NEÓGENO (MIOCENO TEMPRANO, EDAD MAMÍFERO COLHUEHUAPENSE): MICROBIOTHERIA Y POLYDOLOPIMORPHIA
}

\author{
FRANCISCO J. GOIN ${ }^{1,3}$ Y MARÍA ALEJANDRA ABELLO ${ }^{2,3}$ \\ ${ }^{1}$ División Paleontología Vertebrados, Museo de la Plata, Paseo del Bosque s/n, B1900FWA La Plata, Argentina.fgoin@museo.fcnym.unlp.edu.ar \\ ${ }^{2}$ Laboratorio de Sistemática y Biología Evolutiva (LASBE), Museo de la Plata, Paseo del Bosque s/n, B1900FWA La Plata, Argentina. mabello@museo.fcnym.unlp.edu.ar \\ ${ }^{3}$ Consejo Nacional de Investigaciones Científicas y Técnicas (CONICET), Argentina
}

\begin{abstract}
Resumen. En este trabajo se encara la revisión sistemática de dos órdenes de Metatheria (Mammalia) sudamericanos de la Edad Colhuehuapense (Mioceno temprano): Microbiotheria y Polydolopimorphia. En primer lugar, se comentan y discuten las homologías de las cúspides de los molares superiores e inferiores de los Argyrolagoidea (Polydolopimorphia). En segundo lugar, se ofrecen los resultados de un análisis filogenético de los Microbiotheriidae (Microbiotheria). En tercer lugar, se analizan los taxones colhuehuapenses de Microbiotheria y Polydolopimorphia, reconociéndose dos especies nuevas: Orden Microbiotheria, Familia Microbiotheriidae: Pachybiotherium acclinum Ameghino, Pachybiotherium sp., Clenia minuscula Ameghino, Oligobiotherium divisum Ameghino, Eomicrobiotherium mykerum sp. nov., Microbiotherium sp. y Microbiotheriidae indet.; Orden Polydolopimorphia, Suborden Bonapartheriiformes, Superfamilia Argyrolagoidea, Familia Argyrolagidae: Proargyrolagus argentinus sp. nov. y Anargyrolagus primus Carlini, Pascual y Goin; Familia Patagoniidae: Patagonia peregrina Pascual y Carlini; Argyrolagoidea indet. Finalmente, se realiza una adición al conocimiento de los Didelphoidea colhuehuapenses, describiendo una especie indeterminada de esta superfamilia, y un comentario sobre la identidad de "Microbiotherium" gutierrezi Simpson, en el que se reconoce la nueva combinación Coona gutierrezi.
\end{abstract}

Palabras clave. Metatheria. Microbiotheria. Polydolopimorphia. Mioceno temprano. Edad Colhuehuapense. Patagonia. América del Sur.

Abstract. SOUTH AMERICAN METATHERIANS FROM THE BEGINING OF THE NEOGENE (EARLY MIOCENE, COLHUEHUAPIAN LAND-MAMMAL AGE). MICROBIOTHERIA AND POLYDOLOPIMORPHIA. We review the taxonomy of two South American orders of Metatheria (Mammalia) of Colhuehuapian age (early Miocene): Microbiotheria and Polydolopimorphia. First, we comment and discuss on the cusp homologies of the upper and lower molars of the Argyrolagoidea (Polydolopimorphia). Second, we offer results of a phylogenetic analysis of the Microbiotheriidae (Microbiotheria). Third, we analyze all Colhuehuapian Microbiotheria and Polydolopimorphia known up to date: Order Microbiotheria, Family Microbiotheriidae: Pachybiotherium acclinum Ameghino, Pachybiotherium sp., Clenia minuscula Ameghino, Oligobiotherium divisum Ameghino, Eomicrobiotherium mykerum sp. nov., Microbiotherium sp., and Microbiotheriidae indet.; Order Polydolopimorphia, Suborder Bonapartheriiformes, Superfamily Argyrolagoidea, Family Argyrolagidae: Proargyrolagus argentinus sp. nov. and Anargyrolagus primus Carlini, Pascual and Goin; Family Patagoniidae: Patagonia peregrina Pascual and Carlini; Argyrolagoidea indet. Finally, we add knowledge on the Colhuehuapian Didelphoidea, describing an indeterminate species referable to this superfamily, and comment on the identity of "Microbiotherium" gutierrezi Simpson, recognizing the new combination Coona gutierrezi.

Key words. Metatheria. Microbiotheria. Polydolopimorphia. Early Miocene. Colhuehuapian Age. Patagonia. South America.

EsTE trabajo continúa la revisión integral de los mamíferos metaterios sudamericanos del Mioceno temprano (Edad mamífero Colhuehuapense). Goin et al. (2007a) dieron a conocer los contextos estratigráfico, paleoambiental y faunístico, como así también las localidades sudamericanas con niveles portadores de metaterios de esta edad. Se incluyó la revisión sistemática de los órdenes Didelphimorphia y Sparassodonta, más una consideración sobre el estatus taxonómico de los Necrolestidae, considerados allí como Mammalia incertae sedis (véase también Goin et al., en prensa). Se revisan otros dos órdenes de Metatheria colhuehuapenses: Microbiotheria y
Polydolopimorphia. Se discute también un taxón de Didelphoidea de esta edad, así como la identidad de Coona gutierrezi (Del Corro, 1977) n. comb. (Metatheria, Orden indet., Derorhynchidae).

\section{MATERIALES Y MÉTODOS \\ Homologías dentarias}

En la identificación y el establecimiento de las estructuras dentarias homólogas se tuvo en cuenta el criterio de correspondencia topográfica (Rieppel, 1988). Los argirolagoideos incluidos en el análisis fueron: Praedens aberrans Goin, Abello y 
Chornogubsky, 2010, Klohnia major Goin, Abello y Chornogubsky, 2010, Epiklohnia verticalis Goin, Abello y Chornogubsky, 2010, Proargyrolagus bolivianus Wolff, 1984, Proargyrolagus argentinus sp. nov., Anargyrolagus primus Carlini, Pascual y Goin, 2007, Argyrolagus scagliai Simpson, 1970 y Microtragulus reigi Simpson, 1970. Los especímenes estudiados de P. aberrans, $K$. major y $E$. verticalis corresponden a los detallados en Goin et al. (2010a). Los materiales analizados de $P$. argentinus y A. primus se detallan en la sección Paleontología Sistemática. Se incluyeron en las comparaciones los ejemplares más completos y mejor preservados de P. bolivianus, MNHN-Bol-V-003454, A. scagliai, MMMP 785-S, y M. reigi, MMMP 395-S. Excepto en los casos de reinterpretaciones o nuevas propuestas, las homologías y la nomenclatura de las cúspides y crestas adoptadas en este trabajo siguen a Goin et al. (2003, 2010a). Con el fin de indicar los términos utilizados en el análisis y la descripción de la morfología dentaria, en la Figura 1 se muestran el esquema de un molar tribosfénico generalizado y los molares de una selección representativa de argirolagoideos.

\section{Análisis filogenético}

Se realizó un análisis filogenético incluyendo la mayor parte de las especies de Microbiotheria reconocidas hasta el momento: Mirandatherium alipioi (Paula Couto, 1952, pero véase más abajo sobre su asignación al orden), Eomicrobiotherium gaudryi (Simpson, 1964), Eomicrobiotherium mykerum sp. nov., Eomicrobiotherium matutinum Goin, Abello y Chornogubsky, 2010, Oligobiotherium divisum Ameghino, 1902, Microbiotherium tehuelchum Ameghino, 1887, Microbiotherium acicula (Ameghino, 1891), Microbiotherium praecursor (Ameghino, 1898), Microbiotherium patagonicum Ameghino, 1887, Microbiotherium gallegosense Ameghino, 1906, Dromiciops gliroides Thomas, 1894, Clenia minuscula Ameghino, 1904, Clenia brevis Goin, Abello y Chornogubsky, 2010, Pachybiotherium acclinum Ameghino, 1902, Pachybiotherium minor Goin, 1997 y Pachybiotherium illuminatum Goin, Tejedor, Abello y Martin, 2010.

Woodburnodon casei y Marambiotherium glacialis, dos es- pecies de microbioterios procedentes del Eoceno medio de la Antártida (Goin et al., 1999, 2007b), no se incluyeron en el análisis debido a que sus holotipos, únicos materiales referidos, son sumamente fragmentarios. Los Marsupialiformes (Vullo et al., 2009) Alphadon clemensi Eaton, 1993, y Pucadelphys andinus Marshall y Muizon, 1995, se incorporaron al análisis como grupos externos.

La matriz de datos, consistente en 19 taxones y $20 \mathrm{ca}-$ racteres craneodentarios (Apéndice 1, Archivo Suplementario), fue analizada mediante el programa TNT versión 1.0 (Goloboff et al., 2003). Los caracteres multiestado fueron considerados como no ordenados. Se realizó una búsqueda heurística partiendo de 200 árboles de Wagner; se retuvieron 10 árboles por cada secuencia de adición y se aplicó el algoritmo TBR (Tree Bisection Reconection). El soporte de los clados fue medido mediante los métodos Bremer Support relativo y absoluto (Goloboff y Farris, 2001).

Abreviaturas institucionales. DU, Duke University, Durham, EEUU; FMNH, Field Museum of Natural History, Chicago, EEUU; MACN, Museo Argentino de Ciencias Naturales "Bernardino Rivadavia", Ciudad Autónoma de Buenos Aires, Argentina; MACN-A, Colección Ameghino; MACN-CH Colección Chubut; MLP, Museo de La Plata, La Plata, Argentina; MNHN, Muséum national d'Histoire naturelle, París, Francia; MPEF-PV, Museo Paleontológico "Egidio Feruglio", Sección Paleontología Vertebrados, Trelew, Argentina; UNSW, University of New South Wales, Sydney, Australia.

Abreviaturas anatómicas: $\mathrm{C} / \mathrm{c}, \mathrm{dP} 3 / \mathrm{dp} 3, \mathrm{I} / \mathrm{i}, \mathrm{M} / \mathrm{m}$, caninos, tercer premolar deciduo, incisivos y molares superiores/ inferiores, respectivamente; $\mathbf{M x} / \mathbf{m x}$, molar superior/inferior de locus incierto; $\mathbf{P} / \mathbf{p}$, premolares superiores e inferiores, respectivamente; $\mathbf{S t}(\mathbf{A}-\mathbf{E})$, cúspides estilares.

\section{HOMOLOGIAS DENTARIAS DE LOS ARGYROLAGOIDEA}

Según Goin et al. (2010a), tanto Praedens como Klohnia podrían representar argirolagoideos generalizados, cuyos

Figura 1. 1, 10, Patrón molar plesiomorfo de Metatheria/ plesiomorphic molar pattern of Metatheria, 1, molar inferior/ lower molar, 10, molar superior/ upper molar; 2-9, 11-14, patrones molares representativos de Argyrolagoidea/ representative molar patterns of Argyrolagoidea, 2-6, m1 izquierdos en vista oclusal/ left $m 1$ in occlusal views, 6-9, $\mathrm{m} 2$ izquierdos en vista oclusal/ left $m 2$ in occlusal views, 11-12, M2 izquierdos en vista oclusal/ left M2 in occlusal views, 12-13, M2 izquierdos en vista lingual/ left M2 in lingual views. 2, 6, Praedens aberrans; 3, 7, 11, 13, Klohnia major; 4, 8, 12, 14, Proargyrolagus bolivianus; 5, 9, Anargyrolagus primus. cab, cíngulo anterobasal/ anterobasal cingulum; cant, cíngulo anterior/ anterior cingulum; co, crístida oblicua/ cristid obliqua; cpme, cresta premetaconular/ premetaconular crest; cpome, cresta postmetaconular/ postmetaconular crest; E, entocónido/ entoconid; “Ec", ectostílido/ ectostylid; H, hipocónido/ hypoconid; Hpd, hipoconúlido/ hypoconulid; Md, metacónido/ metaconid; M, metacono/ metacone; melo, metacónulo/ metaconule; pc, postcrístida/ postcristid; $\mathbf{P}$, paracono/ paracone; Pad, paracónido/ paraconid; palo, paracónulo/ paraconule; Pd, protocónido/ protoconid; pda, paracrístida/ paracristid; peda, pre-entocrístida/ pre-entocristid; pmda, postmetacrístida/ postmetacristid; ppa, postparacrista/ postparacrista; Pr, protocono/ protocone; prda, postprotocrístida/ postprotocristid; prep, preprotocrista/ preprotocrista; prepa, preparacrista/ preparacrista; prme, premetacrista/ premetacrista; pome, postmetacrista/ postmetacrista; popr, postprotocrista/ postprotocrista; St, cúspide estilar/ stylar cusp. 

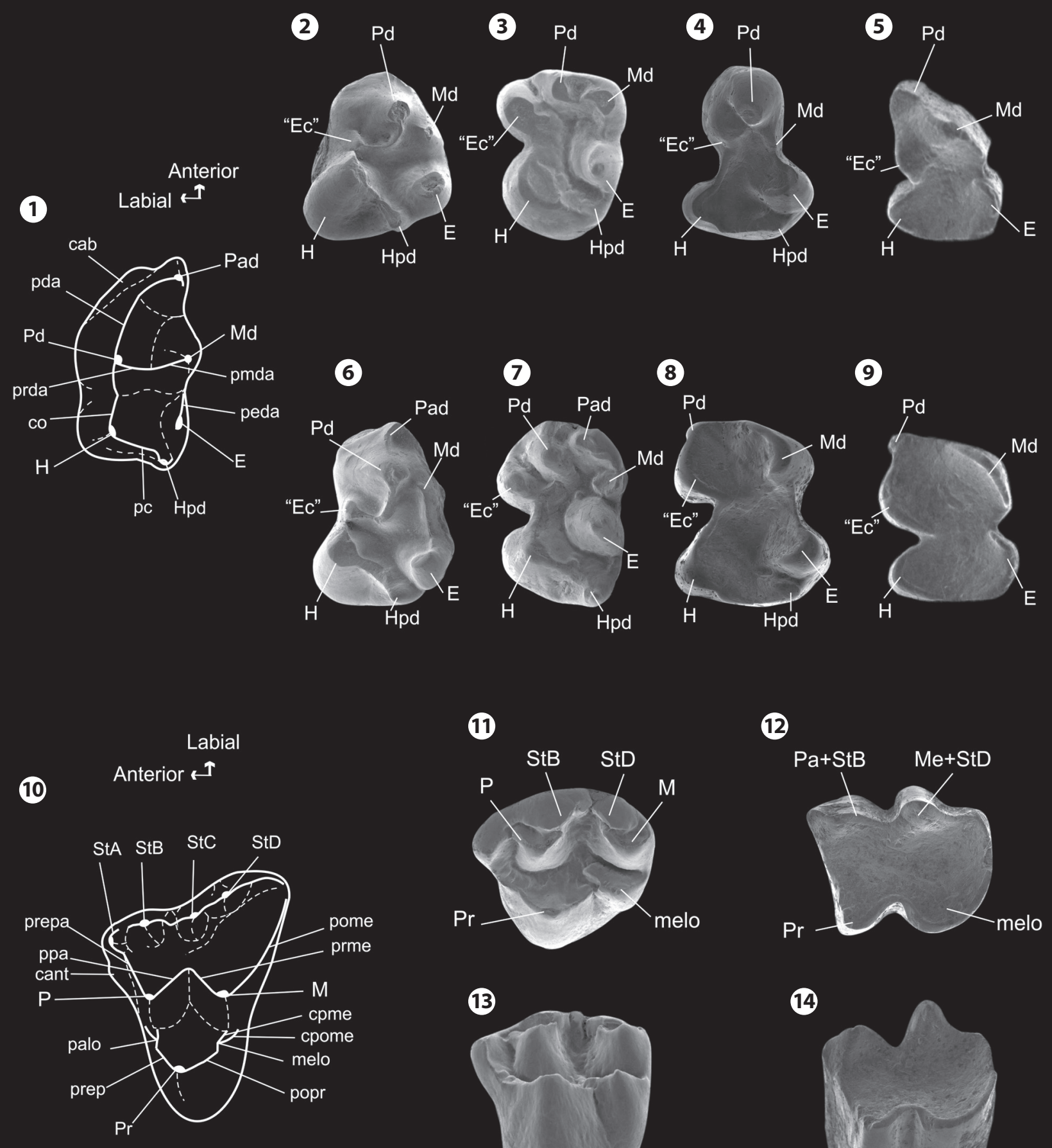

(11)

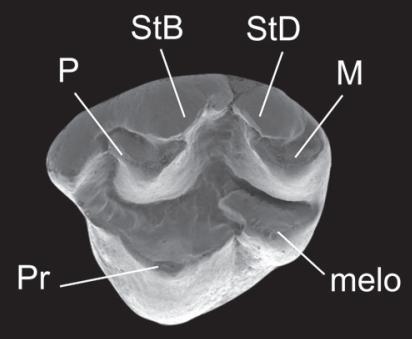

13

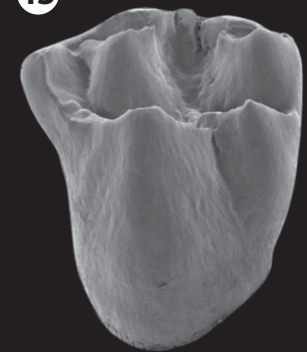

(12)

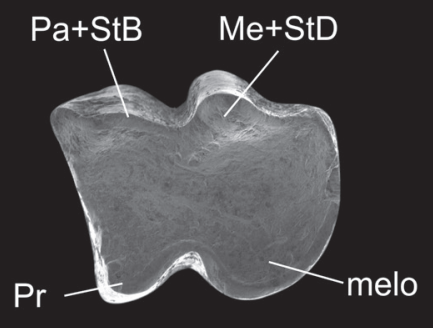

14

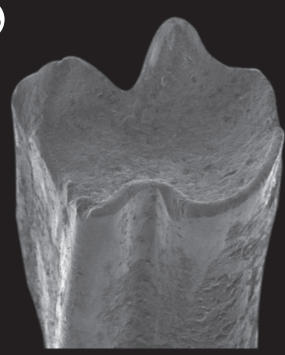


molares, a diferencia de aquellos de los grupos más especializados (e.g., Argyrolagus), presentan un patrón de cúspides y crestas claramente homologable al del molar tribosfénico. Los autores notaron la existencia de cúspides neomórficas en los molares superiores e inferiores. En los molares inferiores de $P$. aberrans y $K$. major, una cúspide neomórfica, denominada ectostílido (Goin et al. 2010a), se ubica labial y posteriormente al protocónido, por delante del hipocónido. En el caso de P. aberrans (Fig. 1.2 y 1.6), esta cúspide se une con la cresta posterior del protocónido, i.e., la postprotocrístida. En esta especie, la postprotocrístida discurre de un modo absolutamente distinto al de la mayor parte de los Metatheria: no se dirige lingualmente hasta contactar con la postmetacrístida (i.e., la cresta que une al metacónido con la postprotocrístida, formando así la metacrístida), sino que desciende por la ladera posterior del protocónido y se orienta hacia la cara labial del diente, uniéndose con el ectostílido. Por el criterio de conectividad (Rieppel, 1994), se sugeriría que, en Praedens aberrans, esta cúspide labial podría tratarse del metacónido desplazado labialmente y que la cresta que une ambas cúspides corresponde a la metacrístida, pero nuestra interpretación difiere por dos motivos: (1) por detrás y lingualmente al protocónido existe una pequeña cúspide cuya ubicación coincide con la del metacónido en el molar tribosfénico generalizado; (2) existen otros casos entre los mamíferos, incluyendo metaterios, del fenómeno conocido como "conversión y captura" de crestas (sensu Hershkovitz, 1971) por parte de otras cúspides en molares superiores e inferiores que explicarían la morfología de P. aberrans. Goin (2006) corroboró parcialmente las observaciones previas de Marshall (1982) sobre la existencia de una estructura neomórfica por detrás y lingualmente al trigónido en Caroloameghinia mater Ameghino, 1901 (Didelphimorphia, Peradectoidea, Caroloameghiniidae). Dicha estructura fue interpretada como una cúspide y denominada "metastílido" por Marshall y "postmetaconúlido" por Hershkovitz (1971, p. 143 y fig. 17B). El "metastílido" es una pequeña cresta ubicada por delante del entocónido. En este caso, la postprotocrístida no conecta con el metacónido, sino con esta cresta. Más aún, la postmetacrístida persiste labialmente al metacónido, pero aparece claramente desconectada de la postprotocrístida. Por el contrario, esta última se extiende por detrás del metacónido hasta conectar con el "metastílido", en realidad una cresta neomórfica (Goin, 2006, fig 1B).

En Klohnia major, el contacto entre el protocónido y el ectostílido es mucho menos evidente, aunque es posible apreciarlo al menos en los $\mathrm{m} 2$ poco desgastados (Fig. $1.3 \mathrm{y}$
1.7). Tanto en Klohnia como en Epiklohnia, esta neocúspide adquiere un tamaño considerable, al punto de formar buena parte de la esquina anterolabial del diente, especialmente en los molares más posteriores. Sobre la base de este esquema de homologías, proponemos aquí que la cúspide principal de la esquina posterolabial de los $\mathrm{m} 2-\mathrm{m} 3$ de Proargyrolagus (Fig. 1.4 y 1.8) y los argirolágidos más derivados (Anargyrolagus [Fig. 1.5 y 1.9], Argyrolagus, Microtragulus y Hondalagus; Sánchez-Villagra et al., 2000) corresponde al ectostílido y no al protocónido, como fue propuesto previamente (SánchezVillagra y Kay, 1997; véase más abajo). En síntesis, postulamos que tanto la presencia de una cúspide neomórfica labial (el ectostílido) como el proceso de "conversión y captura" (sensu Herhkovitz, 1971) de la postprotocrístida constituyen rasgos característicos de los Argyrolagoidea.

En su revisión de Proargyrolagus bolivianus, Sánchez-Villagra y Kay (1997) identificaron las cuatro cúspides principales que integran los lóbulos anterior (trigónido) y posterior (talónido) de los molares inferiores: protocónido (labial) y metacónido (lingual), en el lóbulo anterior, e hipocónido (labial) y entocónido (lingual) en el lóbulo posterior. Nuestra hipótesis de homología difiere de esta propuesta en la interpretación de las principales estructuras del trigónido. En nuestra opinión, se identifican dos cúpides labiales, el protocónido y el ectostílido, ubicados en las esquinas anterolabial y posterolabial, respectivamente. Tal como se aprecia en los molares de Klhonia major, la cúspide anterior al ectostílido se corresponde con el protocónido (Fig. 1.3 y 1.7). Al respecto, vale la pena señalar que, en los propios esquemas dentarios ofrecidos por SánchezVillagra y Kay (1997, fig. 7B), dicha cúspide (muy pequeńa e innominada por los autores) aparece por delante del ectostílido. Aún más claramente puede apreciarse el protocónido en el calco del ejemplar MNHN-Bol-V-003454 de P. bolivianus (el ejemplar original se perdió con posterioridad a su estudio; R. Kay, com. pers.). Otra diferencia entre nuestras observaciones y aquellas ofrecidas por estos últimos autores es que, al menos en los molares inferiores de la nueva especie aquí descripta de Proargyrolagus, no se aprecia una cúspide basal y anterior al metacónido, estructura homologada por Sánchez-Villagra y Kay (1997) con el paracónido.

A diferencia de Praedens, los molares superiores de Klohnia (Fig. 1.11 y 1.13) y Epiklohnia no muestran cúspides neomórficas (Goin et al., 2010a), pudiendo establecerse las homologías respectivas sin mayores dificultades. No obstante, debe notarse que posiblemente varias de las superficies coronales de estos molares están profundamente modificadas con respecto al patrón tribosfénico generalizado. En ambos, 
pero sobre todo en Epiklohnia verticalis, es difícil precisar, por ejemplo, la extensión real de la cuenca del trígono. En efecto, la ladera labial del protocono se ubica en posición excéntrica en relación con el área basal a las laderas linguales del paracono y el metacono. Es indudable que la existencia de cúspides neomórficas en los molares inferiores tiene una correspondencia con las superficies que actúan como antagonistas oclusales en los molares superiores. Hasta tanto no se realice un análisis morfofuncional sobre la oclusión dentaria en estas especies, resultará difícil precisar la entidad de las superficies neomórficas de los molares superiores.

$\mathrm{Al}$ igual que en el molar inferior, el patrón molar superior de los argirolagoideos más especializados (e.g., Proargyrolagus; Fig. 1.12 y 1.14) puede derivarse del patrón molar existente en Klohnia. La esquina anterolabial está ocupada por la StA. En Klohnia y Epiklohnia se observa que tanto el paracono y la $\mathrm{StB}$, por un lado, como el metacono y la StD, por el otro, están apareados y prácticamente fusionados. Por su parte, la cara lingual del diente incluye al protocono (anterior) y al metacónulo (posterior); estas cúspides están separadas por un entoflexo. En Proargyrolagus, Anargyrolagus, Argyrolagus, Microtragulus y Hondalagus se observan dos cúspides labiales principales que son homólogas al paracono+StB (la anterior) y al metacono+StD (la posterior), interpretación que difiere de la ofrecida por Sánchez-Villagra y Kay (1997, fig 7A).

\section{ANALISIS FILOGENETICO DE LOS MICROBIOTHERIIDAE}

Como resultado del análisis filogenético, se obtuvo un árbol más parsimonioso (Fig. 2) de 33 pasos de largo (CI= 66 y RI= 81). Los Microbiotheria sensu Marshall (1987) no constituyen un agrupamiento natural. Por un lado, todos los microbioterios, excepto Mirandatherium alipioi, conforman un clado; por el otro, $M$. alipioi resultó el grupo hermano de Pucadelphys andinus. Mirandatherium Paula Couto, 1952, fue referido alternativamente a los Microbiotheriidae (Marshall, 1987) y a los Didelphidae (Marshall et al., 1990; Oliveira, 1998). Si bien el objetivo del presente trabajo no fue testear la monofilia de los Microbiotheria, su resultado indica que M. alipioi no forma parte de dicho clado, y por lo tanto refuerza las hipótesis de su pertenencia a un linaje distinto (contra Oliveira y Goin, 2011).

Se recuperaron dos clados mayores de microbiotéridos. Uno de ellos agrupa a Dromiciops gliroides y todas las especies de Microbiotherium Ameghino, 1887, excepto M. gallegosense. Aquí, las relaciones entre las especies permanecen ambiguas, excepto por la relación de grupos hermanos entre
M. tehuelchum y $M$. praecursor. El clado restante, parcialmente resuelto, agrupa a Eomicrobiotherium (E. gaudryi+E. mykerum+E. matutinum), Oligobiotherium divisum, Microbiotherium gallegosense y a las especies de Clenia y Pachybiotherium. Estas últimas constituyen un clado terminal $(P$. minor $+P$. acclinum $+P$. illuminatum) que tiene como grupo hermano a Clenia minuscula. Clenia brevis constituye el grupo hermano de Clenia minuscula+Pachybiotherium, por lo que Clenia no es un agrupamiento natural. Microbiotherium gallegosense y Oligobiotherium divisum se resuelven como sucesivos grupos hermanos del clado C. brevis+ $(C$. minuscula+Pachybiotherium).

El clado de Microbiotheriidae está bien soportado por los valores absolutos y relativos del Bremer Support y está sustentado por ocho sinapomorfías: hipocónido de los m1-m3 bien saliente (7[1]), ausencia de cíngulo posterior en los molares inferiores (13[1]), cíngulo anterobasal de los molares inferiores reducido o ausente (14[1]), protoconos anchos (15[1]), paracónulos y metacónulos vestigiales a ausentes (16[1]), plataforma estilar de los M2-M3 muy reducida anterior y posteriormente (18[1]), cúspides estilares moderadamente reducidas (19[1]) y preparacrista corta, oblicua y terminando en la StA (20[1]). Dentro de este clado, las relaciones inferidas entre algunas especies no son consistentes con las hipótesis filogenéticas y clasificaciones previas (Marshall, 1982; Marshall et al., 1990; Goin et al., 2010a). Nuestros resultados no apoyan la sinonimia propuesta por Marshall (1982) entre Oligobiotherium y Clenia y corroboran la validez de ambos, tal como fue propuesta por Goin et al. (2010a). En este análisis se recuperó la monofilia de Pachybiotherium y Eomicrobiotherium, sustentando la pertenencia a Pachybiotherium de las especies $P$. minor y P. illuminatum (Goin, 1991; Goin et al., 2010b) y a Eomicrobiotherium de las especies E. mykerum sp. nov. y E. matutinum (Goin et al., 2010a). Por el contrario, en este análisis no se recuperó la monofilia de Microbiotherium (sensu Marshall, 1982). Por un lado, las especies $M$. patagonicum, M. acicula, M. tehuelchum y $M$. praecursor constituyen un clado junto a $D$. gliroides; por el otro, M. gallegosense se agrupa con las especies de Oligobiotherium, Clenia y Pachybiotherium (Fig. 2). Si bien en este trabajo Microbiotherium y Dromiciops forman un grupo natural, optamos por no innovar en la taxonomía, por lo que nos referiremos a Dromiciops gliroides como un taxón válido, al tiempo que referiremos, con dudas, la especie gallegosense a "Microbiotherium". Del mismo modo, con relación al estatus taxonómico de las especies de Clenia, referiremos con dudas la especie brevis a "Clenia". 


\section{PALEONTOLOGÍA SISTEMÁTICA}

Infraclase Metatheria Huxley, 1880

Supercohorte Marsupialia Gill, 1872

Cohorte Australidelphia Szalay, 1982

Orden Microbiotheria Ameghino, 1889

Familia Microbiotheriddae Ameghino, 1887

Género Pachybiotherium Ameghino, 1902

1902. Pachybiotherium Ameghino, p. 123; Simpson, 1932, p. 3; Reig, 1955, p. 121; Goin, 1997, p. 188.

Especie tipo. Pachybiotherium acclinum Ameghino, 1902.

Especies incluidas. P. acclinum, P. minor Goin, 1997, у P. illuminatum Goin, Tejedor, Abello y Martin, 2010.
Distribución. Mioceno temprano-medio, América del Sur. Diagnosis enmendada. Pachybiotherium se diferencia de los restantes géneros de Microbiotheria por la siguiente combinación de caracteres: rama horizontal mandibular muy alta; sobre su borde alveolar, la rama horizontal no es uniforme, sino más baja en la parte anterior, de forma que el plano alveolar de los premolares es más bajo que aquel de la serie molar; $\mathrm{M} 4 / \mathrm{m} 4$ relativamente poco reducido respecto de los $\mathrm{M} 3 / \mathrm{m} 3$; molares inferiores con el protocónido de los $\mathrm{m} 1-\mathrm{m} 2$ inclinado lingualmente y el hipocónido de los $\mathrm{m} 1-\mathrm{m} 3$ poco saliente; protocono muy ancho anteroposteriormente en los M1-M3. Emended diagnosis. Pachybiotherium differs from other $\mathrm{Mi}$ crobiotheria in the following combination of characters: very high

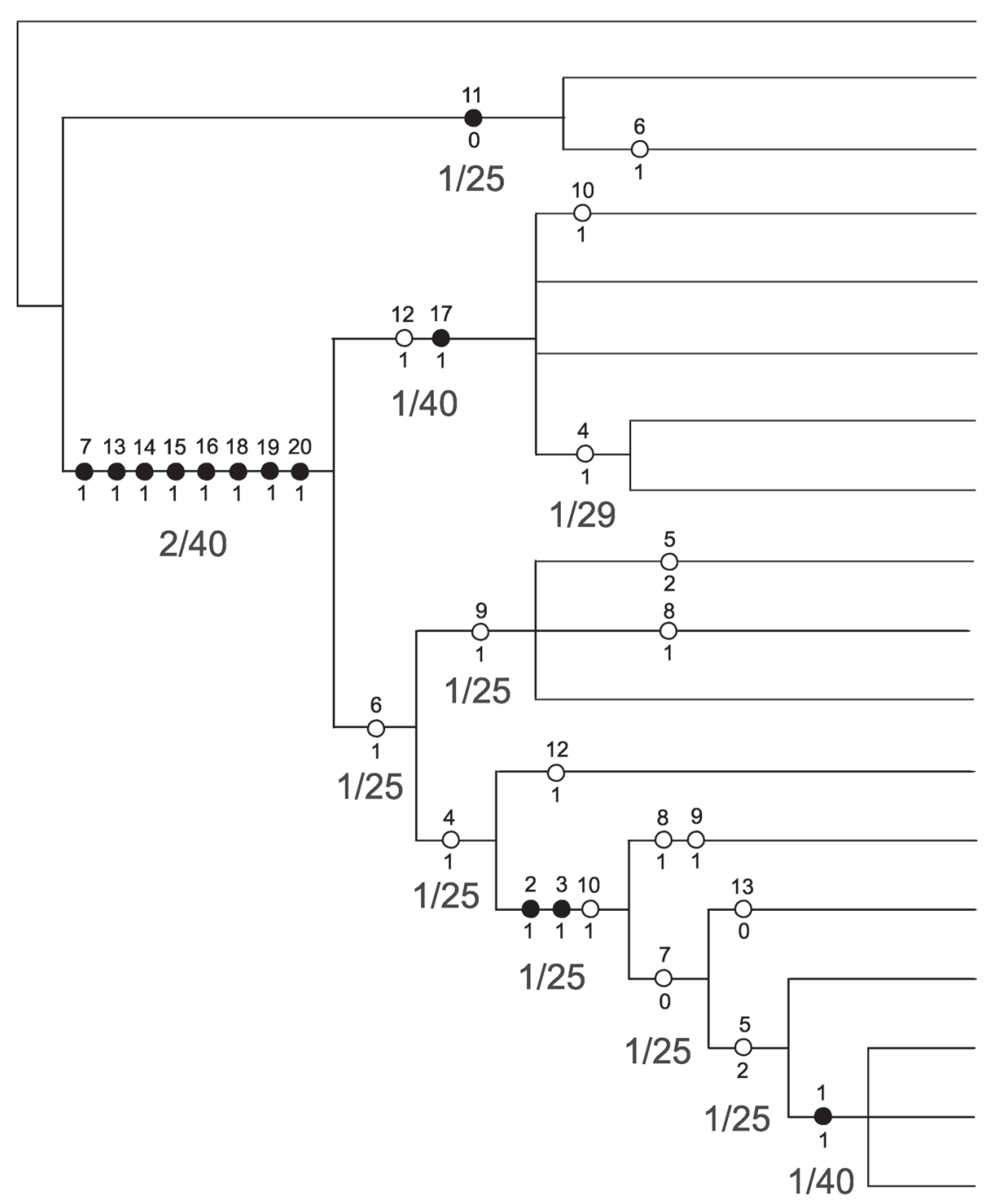

Alphadon clemensi

Pucadelphys andinus

Mirandatherium alipioi

Microbiotherium patagonicum

Microbiotherium acicula

Dromiciops gliroides

Microbiotherium tehuelchum

Microbiotherium praecursor

Eomicrobiotherium gaudryi

Eomicrobiotherium mykerum

Eomicrobiotherium matutinum

Oligobiotherium divisum

Microbiotherium gallegosense

Clenia brevis

Clenia minuscula

Pachybiotherium acclinum

Pachybiotherium illuminatum

Pachybiotherium minor

Figura 2. Árbol filogenético de Microbiotheriidae (largo=33) obtenido a partir del análisis de parsimonia. En los nodos se indican las sinapomorfías no ambiguas; los círculos negros representan sinapomorfías no homoplásicas, los círculos blancos sinapomorfías homoplásicas y los números encima y debajo de cada una indican los números de carácter y estado, respectivamente. Debajo de los nodos se indican los valores de soporte de Bremer absoluto y relativo/ phylogeny of Microbiotheriidae. Single most parsimonious tree (length $=33$ ) resulting from parsimony analysis. For each node the list of the non-ambiguous synapomorphies is given; black circles represent non-homoplasious synapomorphies, open circles homoplasious synapomorphies, and numbers above and below circles represent character number and character state, respectively. Absolute and relative Bremer support values are indicated below each node. 
horizontal ramus; on its alveolar edge, the horizontal ramus decreases sharply in height in the anterior portion, in such a way that the premolar alveolar series is at a lower level than the molar one; M4/m4 only slightly reduced in relation to M3/m3; lingually inclined protoconid of $m 1-m 2$; hipoconid in $m 1-m 3$ not labially salient; protocone of M1-M3 very wide anteroposteriorly.

Comentarios. Marshall (1982) refirió originalmente Pachybiotherium a los Didelphidae, al igual que las especies casamayorenses Eomicrobiotherium gaudryi (Simpson, 1964) y E. gutierrezi (Del Corro, 1977). Posteriormente, Reig et al. (1987) incluyeron a Pachybiotherium entre los didélfidos calurominos, considerando a Eomicrobiotherium como un Didelphoidea incertae sedis. En el mismo año, sin embargo, Marshall (1987) incluyó a Pachybiotherium y a Eomicrobiotherium, junto con Dromiciops, Microbiotherium y Mirandatherium, entre los Microbiotheriidae, Superfamilia Microbiotherioidea, Suborden Didelphimorphia. Marshall et al. (1990; ver también Goin, 1991) también refirieron todos estos géneros a la Familia Microbiotheriidae, aunque esta vez en el Orden Microbiotheria, Cohorte Australidelphia, criterio seguido en este trabajo.

\section{Pachybiotherium acclinum Ameghino, 1902}

1902. Pachybiotherium acclinum Ameghino, p. 123; Reig 1955, p. 125.

1953. Microbiotherium acclinum Ringuelet, p. 277.

Holotipo. Fragmento mandibular izquierdo con el alvéolo del canino, raíces del p1 y $\mathrm{m} 2$, raíz anterior y parte del alvéolo posterior del m4 y los p2, p3, m1 y m3 completos; MACN-A 52-370a.

Material referido. Fragmento mandibular derecho con los alvéolos del p1 y p2-m3 completos, MLP 82-V-2-111; fragmento mandibular derecho con los alvéolos de los i1-p3 y los m1-m3 completos, MLP 92-X-10-10; fragmento mandibular izquierdo con p3-m1 y raíces de los m2-m3, MPEFPV 551; mandíbula izquierda completa con el alvéolo del canino, raíces de los p1-p3, m1-m2 completos y raíces de los m3-m4, MPEF-PV 6534.

Procedencia geográfica y estratigráfica. Barranca Sur del lago Colhue Huapi (Departamento Sarmiento, Provincia de Chubut, Argentina). Formación Sarmiento, Miembro Colhue Huapi. Mioceno temprano (Edad mamífero Colhuehuapense). Medidas. Se detallan en el Apéndice 2 (Archivo Suplementario en línea).

Diagnosis enmendada. Se diferencia de las otras dos especies del género por el menor tamaño del entocónido; de $P$. illuminatum, por la mayor separación entre el hipoconúlido y el entocónido, y por la posición más vertical del protocóni- do; de $P$. minor, por su altura mandibular proporcionalmente menor, la posición menos retrasada del metacónido respecto del protocónido y la mayor gracilidad del hipoconúlido.

Emended diagnosis. Differs from other species of the genus in its smaller entoconid; from $\mathrm{P}$. illuminatum by having hypoconulid and entoconid more distant from each other, and more vertical protoconid; from P. minor in its relatively shallower mandible, metaconid less posteriorly placed with respect to protoconid, and its more gracile hypoconulid.

Descripción. El ejemplar MLP 92-X-10-10 muestra su porción distal bien preservada. El cuerpo mandibular por debajo del p3 presenta algún tipo de patología ósea (Marshall, 1978, p.12). Se aprecia una escasa profundidad en las caras lingual y posterior del alvéolo del canino, las cuales son fuertemente trabeculadas y rugosas, posiblemente como resultado de un crecimiento anómalo del tejido esponjoso mandibular. El foramen mentoniano anterior es muy grande y se ubica por debajo del $\mathrm{p} 2$, mientras que el posterior es más pequeńo y abre por debajo del $\mathrm{m} 1$. En los ejemplares MLP 92-X-10-10, MLP 82-V-2-111 y MPEF-PV 6534 que han preservado los alvéolos y/o dientes de la serie p1-p3, se pueden observar dos rasgos distintivos de $P$. acclinum: el p3 es mucho más grande que los p1-p2 y la implantación del p1 es claramente oblicua, con la raíz posterior ubicada lingualmente respecto de la raíz anterior. La morfología de los molares preservados en los ejemplares estudiados concuerda con la del holotipo: paracónidos muy reducidos y, en los $\mathrm{m} 2-\mathrm{m} 4$, bien comprimidos anteroposteriormente; cíngulo anterobasal ausente; protocónido con la cúspide no estrictamente vertical, sino algo inclinada lingualmente; metacónido de los m1-m4 implantado algo posteriormente con respecto al protocónido; talónidos amplios, pero con el hipocónido poco saliente. En todos los ejemplares observados, incluyendo el holotipo, la hilera dentaria en vista oclusal es arqueada, mostrando un leve ángulo entre la serie de los premolares y la de los molares.

Comentarios. Un detalle peculiar de la morfología mandibular de Pachybiotherium y otros microbiotéridos (véase más abajo) es que las series premolar y molar no se orientan en el mismo plano alveolar, sino que los molares se ubican por encima del plano de implantación de los premolares. En otras palabras, el borde alveolar de la rama horizontal no es recto sino que desciende abruptamente, inmediatamente por delante del m1. Este rasgo no es exclusivo de Pachybiotherium, siendo compartido por Clenia minuscula y "Microbiotherium" gallegosense. Ahora bien, en tres de los seis ejemplares de Pachybiotherium estudiados (MPEF-PV 6534, MLP 82V-2-111 y MLP 92-X-10-10), dicha diferencia de altura es 
mucho más notoria que en los restantes (MPEF-PV 5839, MPEF-PV 551 y el holotipo MACN-A 52-370a). La manifestación de este carácter (afinamiento mandibular anterior más o menos abrupto) parece correlacionarse con el largo relativo del rostro (longitud entre el $\mathrm{m} 1 \mathrm{y}$ el canino). En los dos ejemplares con afinamiento mandibular pronunciado, puede apreciarse que la distancia entre el extremo anterior del m1 y, al menos, el borde alveolar posterior del canino es claramente mayor que en los ejemplares con afinamiento mandibular menos notorio. En nuestra opinión, la identidad en la morfología dentaria de estos especímenes asegura la pertenencia de todos ellos a una misma especie, obedeciendo más probablemente estas diferencias en la implatanción de la serie yugal a variabilidad intraespecífica, probablemente vinculada con la edad o el sexo. Otros rasgos que muestran cierta variabilidad entre los especímenes referidos a $P$. acclinum son: el tamańo relativamente pequeño de los molares en el ejemplar MLP 92-X-10-10; el menor ancho relativo del trigónido del $\mathrm{m} 1$ y la mayor proyección labial de los hipocónidos de los $\mathrm{m} 1-\mathrm{m} 3$ en los especímenes MLP 92-X-1010 y MLP 82-V-2-111; y la ubicación más distante de los hipoconúlidos respecto de los entocónidos de los $\mathrm{m} 1-\mathrm{m} 2$, ocupando una posición más central en los talónidos en el ejemplar MLP 92-X-10-10.

La persistencia del área incisiva, incluyendo alvéolos y/o raíces de los i2-i5, en MLP 92-X-10-10 y en el ejemplar asignado a Pachybiotherium sp., MPEF-PV 5676 b, permite confirmar un rasgo único de los Microbiotheriidae entre los metaterios "poliprotodontes": la ausencia de un i3 sobremontado. $\mathrm{Al}$ igual que ocurre en Dromiciops gliroides, la única especie viviente del Orden Microbiotheria, el segundo incisivo inferior (i3 de la nomenclatura de Hershkovitz, 1982) está alineado con los restantes dientes de la serie; esto es, no existe un puente o trabécula ósea bucal entre el i 2 y el i4 que indique una implantación más lingual del i3. Tanto los alvéolos (MPEF-PV 5676 b) como los alvéolos y raíces (MLP 92-X-10-10) de los especímenes de Pachybiotherium muestran no sólo un perfecto alineamiento, sino una morfología similar: las raíces están comprimidas mesiodistalmente, por lo que su diámetro bucolingual es mucho mayor.

Pachybiotherium cf. P. acclinum Ameghino, 1902

Material referido. Fragmento mandibular izquierdo con los alvéolos de los i2-p2, MPEF-PV 5676b; fragmento mandibular derecho sin dientes, MPEF-PV 5839.

Procedencia geográfica y estratigráfica. Barranca Sur del lago Colhue Huapi (Departamento de Sarmiento, Provin- cia de Chubut, Argentina). Formación Sarmiento, Miembro Colhue Huapi. Mioceno temprano (Edad mamífero Colhuehuapense).

Descripción y comentarios. El ejemplar MPEF-PV 5676 $\mathrm{b}$ consiste en un resto mandibular edéntulo cuyos rasgos generales coinciden con los de Pachybiotherium acclinum. Según puede observarse en los alvéolos de la serie incisiva, el segundo incisivo inferior no estaba sobremontado; asimismo, la sínfisis mandibular es corta, llegando posteriormente hasta un punto por debajo de la raíz posterior del p2; ambos caracteres confirman la pertenencia de este ejemplar a los Microbiotheriidae. Su tamaño y la morfología alveolar coinciden con otros ejemplares de $P$. acclinum; la altura del cuerpo mandibular, sin embargo, es menor que en ellos. Asimismo, a juzgar por el alvéolo del canino, este diente no era de implantación subvertical, sino algo procumbente, lo que también lo diferencia de los ejemplares conocidos de $P$. acclinum. Tanto la altura del cuerpo mandibular como la semiprocumbencia del canino inferior podrían deberse a que este ejemplar corresponde a un individuo subadulto.

\section{Género Clenia Ameghino, 1904}

1904. Clenia Ameghino, p. 260; Ringuelet, 1953, p. 281.

1906. Clenialites Ameghino, p. 422.

1953. Microbiotherium Ringuelet, p. 277.

Especie tipo. Clenia minuscula Ameghino, 1904

Especies incluidas. La especie tipo solamente (véanse los comentarios a $C$. minuscula más abajo).

Distribución. Patagonia central, Mioceno temprano (Edad mamífero Colhuehuapense).

Diagnosis. Como la de la especie tipo.

\section{Clenia minuscula Ameghino, 1904}

Figura 3.1-6

1904. Clenia minuscula Ameghino, p. 260; Ringuelet 1953: p. 281. 1906. Clenialites minusculus Ameghino, p. 422, fig. 315; Ameghino 1907, fig. 1.

1955. Oligobiotherium divisum Reig, p. 121.

1982. Microbiotherium divisum Marshall, p. 22.

Holotipo. Un fragmento mandibular izquierdo con los $\mathrm{m} 1-$ m2, MACN-A 52-381.

Material referido. Fragmento mandibular izquierdo con el p2, MLP 82-V-2-88; fragmento mandibular derecho con $\mathrm{m} 2-\mathrm{m} 3$, MLP 83-III-I-204b; fragmento mandibular izquierdo con los alvéolos de los $\mathrm{p} 3$ y $\mathrm{m} 1$ completo, MPEFPV 4746; fragmento mandibular izquierdo con $\mathrm{p} 3-\mathrm{m} 2$, MPEF-PV 4750; fragmento mandibular derecho sin dientes, MPEF-PV 4751; fragmento mandibular izquierdo con 
p3-m1, MPEF-PV 5677; fragmento mandibular derecho con el m4, MPEF-PV 5859; fragmento mandibular izquierdo con alvéolos y raíces de los p1-p3 y m4 y los m1-m3 completos (Fig. 3.1-2), MPEF-PV 6017; m1 izquierdo, MPEF-PV 4738; $\mathrm{m} 1$ izquierdo, MPEF-PV 4747; $\mathrm{m} 1$ izquierdo, MPEF-PV 4748; $\mathrm{m} 1$ izquierdo, MPEF-PV 4749; m1 izquierdo, MPEF-PV 4933; m1 derecho, MPEF-PV 4968; $\mathrm{m} 1$ izquierdo, MPEF-PV 6023; $\mathrm{m} 2$ derecho, MPEFPV 4743; m2 izquierdo, MPEF-PV 4744; m2 izquierdo, MPEF-PV 4745; m2 izquierdo, MPEF-PV 4965; m2 izquierdo, MPEF-PV 4998; m3 izquierdo, MPEF-PV 4935; m3 izquierdo, MPEF-PV 4937; m3 derecho, MPEF-PV 4742; m3 derecho incompleto, MPEF-PV 4957; m3 izquierdo, MPEF-PV 5285; m4 derecho, MPEF-PV 4942; fragmento de maxilar izquierdo con P3-M1 (Fig. 3.3-4), MPEF-PV 4912; M1 derecho, MPEF-PV 4914; M1 derecho incompleto, MPEF-PV 4955; M2 izquierdo, MPEF-PV 4915; M2 izquierdo (Fig. 3.5-6), MPEF-PV 4974; M3 izquierdo, MPEF-PV 4916; MPEF-PV 6028, M3 izquierdo.

Procedencia geográfica y estratigráfica. Barranca Sur del lago Colhue Huapi (Departamento Sarmiento, Provincia de Chubut, Argentina). Formación Sarmiento, Miembro Colhue Huapi. Mioceno temprano (Edad mamífero Colhuehuapense). Los ejemplares MPEF-PV 4750, MPEF-PV 4748, MPEF-PV 4749, MPEF-PV 4743, MPEF-PV 4742, MPEF-PV 4744, MPEF-PV 4738, MPEF-PV 4747, MPEFPV 4751, MPEF-PV 4746 y MPEF-PV 4745 proceden del "nivel C"; los ejemplares MPEF-PV 4942, MPEF-PV 4937, MPEF-PV 4935, MPEF-PV 4933, MPEF-PV 4926, MPEFPV 4915, MPEF-PV 4914 y MPEF-PV 4912 proceden del "nivel C Gris"; el ejemplar MPEF-PV 4974 procede del "nivel 'B”'; el ejemplar MPEF-PV 4998 procede de "Mono 2", el ejemplar MPEF-PV 5285 del nivel "Mono Oeste Superficial" y los ejemplares MPEF-PV 4968, MPEF-PV 4965, MPEFPV 4957 y MPEF-PV 4955 proceden de "Mono Este Superficial". El resto de los ejemplares aquí referidos no tiene una procedencia específica más allá del Miembro Colhue Huapi.

Medidas. Se detallan en el Apéndice 2 (Archivo Suplementario en línea).

Diagnosis enmendada. Clenia minuscula se diferencia de los restantes Microbiotheria por la siguiente combinación de caracteres: protocónido de los $\mathrm{m} 1-\mathrm{m} 2$ inclinado lingualmente; hipocónido de los m1-m3 poco saliente; paracónido de los $\mathrm{m} 1-\mathrm{m} 2$ comprimido anteroposteriormente; rama horizontal mandibular baja; escasa diferencia de tamaño entre los M3/ m3 y M4/m4; postcrístida de los $\mathrm{m} 1-\mathrm{m} 2$ orientada perpendicularmente al eje dentario.
Emended diagnosis. Differs from other Microbiotheria in the following combination of characters: lingually inclined protoconid in $m 1-m 2$; hypoconid of $m 1-m 3$ slightly salient labially; paraconid of m1-m2 antero-posteriorly compressed; horizontal ramus proportionally low; only slight difference in size between $M / m 3$ and $M / m$ 4, postcristid of $m 1-m 2$ transverselly oriented with respect to the dental axis.

Descripción. El ejemplar MLP 82-V-2-88 ha preservado la región incisiva del cuerpo mandibular; al igual que en $\mathrm{Pa}$ chybiotherium, esta es proporcionalmente más corta que en otros Microbiotheriidae, si bien los alvéolos de los i1-i4 son de sección más subcircular que en los de aquel género (i.e., más comprimidos anteroposteriormente). El alvéolo del i4, parcialmente preservado, sugiere que el i4 era un tercio más pequeño que los i1-i3. Si bien comparte una morfología general similar a la de otros miembros de esta familia, en el p2 del ejemplar MLP 82-V-2-88, la cresta anterior no desciende abruptamente, sino que se dispone de forma casi subhorizontal. A juzgar por sus alvéolos preservados, el p3 era claramente más grande que el p2. Los premolares se disponen casi sin diastemas entre sí, aunque parece existir una pequeña separación entre el p3 y el m1 en el ejemplar MPEF-PV 6017. Los molares inferiores tienen un aspecto general similar a los de Pachybiotherium, sobre todo en su mitad posterior; el carácter muy poco saliente de los hipocónidos hace que los talónidos adquieran un aspecto subcuadrangular en vista oclusal. Como en el resto de los microbiotéridos, los hipocónidos son menos salientes en los molares posteriores que en los anteriores, por lo que en el m3, por ejemplo, el talónido parece aún más rectangular que el del m1. En los m1-m3, el paracónido está bien comprimido en sentido anteroposterior. El hipoconúlido no está particularmente alejado del entocónido, como ocurre en "Microbiotherium" gallegosense, Eomicrobiotherium y, en menor medida, en algunos ejemplares de Pachybiotherium acclinum.

Los molares superiores MPEF-PV 4915, MPEF-PV 4974 y MPEF-PV 4916 tienen protoconos muy anchos (i.e., su diámetro anteroposterior es casi el mismo que el diámetro labiolingual), más que en cualquier otro microbiotérido colhuehuapense, y delimitan cuencas del trígono muy amplias. Pachybiotherium illuminatum, del "Pinturense" de la Provincia de Santa Cruz, también se caracteriza por poseer protoconos muy anchos (Goin et al., 2010b). Tanto el paracónulo como el metacónulo, aunque reducidos, están presentes, siendo el metacónulo de mayor tamańo. En el M2, la plataforma estilar está menos desarrollada que en Oligobiotherium, siendo las cúspides estilares menos notorias. Las 
laderas posterolabial del paracono y anterolabial del metacono son abruptas y delimitan hacia el centro de la plataforma estilar un área de contorno subtriangular y relativamente plana, rasgo que distingue a los molares superiores de Clenia de los de otros microbiotéridos. Los M2 y M3 son similares y se diferencian por la postmetacrista más corta del M3. Comparado con Oligobiotherium, las cúspides estilares están algo más desarrolladas, en especial la StB.

Comentarios. Los nuevos materiales permiten revaluar el concepto de Clenia minuscula, previamente conocida sólo a través de su holotipo. Siguiendo a Ringuelet (1953) y Reig (1955), Marshall (1982, p. 22) sinonimizó a Clenia minuscula con Oligobiotherium divisum y a ambos géneros con Microbiotherium (Marshall, 1982, p. 11). Con el beneficio de una muestra mucho mayor, queda claro que Clenia minuscula es una especie válida y distinta de Oligobiotherium divisum. Por otra parte, los resultados del análisis filogenético no apoyan las hipótesis que sostenían la pertenencia de Clenia minuscula a Microbiotherium o a Oligobiotherium (ver los resultados y la discusión del análisis filogenético). Por el contrario, se desprende la condición de grupos hermanos entre Clenia minuscula y Pachybiotherium, compartiendo el protocónido de los molares inferiores inclinado (arqueado) lingualmente en los $\mathrm{m} 1-\mathrm{m} 2$. Si bien el cuerpo mandibular de Clenia minuscula es relativamente alto en relación al resto de los Microbiotheriidae, no alcanza la altura relativa de las especies de Pachybiotherium (Tabla 1 en el Apéndice 1, Archivo Suplementario en línea), por lo que revalidamos a Clenia como género válido de los Microbiotheriidae.

\section{Género Oligobiotherium Ameghino, 1902}

1902. Oligobiotherium Ameghino, p. 124.

1932. Microbiotherium Simpson, p.2; Pascual y Odreman Rivas, 1971, p. 387; Marshall, 1982, p. 22.

1953. Microbiotheridion Ringuelet, p. 280.

1971. ?Microbiotherium Pascual y Odreman Rivas, p. 387.

Especie tipo. Oligobiotherium divisum Ameghino, 1902.

Especies incluidas. La especie tipo solamente.
Distribución. Patagonia central, Mioceno temprano (Edad mamífero Colhuehuapense).

Diagnosis. Como la de la especie tipo.

\section{Oligobiotherium divisum Ameghino, 1902} Figura 3.7-10

1902. Oligobiotherium divisus (sic) Ameghino, p. 124; Ringuelet, 1953, p. 268.

1930. Oligobiotherium divisum Simpson, p. 36; Reig, 1955, p. 121.

1932. Microbiotherium hernandezi Simpson, p. 2; Pascual y Odreman Rivas, 1971, p. 387.

1953. Microbiotheridion hernandezi Ringuelet, p. 280; Reig, 1955, p. 152.

1971. ?Microbiotherium divisus (sic) Pascual y Odreman Rivas, p. 387. 1982. Microbiotherium divisum Marshall, p. 22.

Holotipo. Fragmento mandibular izquierdo con la raíz posterior del m2, m3 sin el metacónido y el entocónido y raíces del m4, MACN-A 52-374.

Material referido. Fragmento mandibular izquierdo con alvéolos del i2-p3 y m1 completo, MLP 83-III-I-204a; fragmento mandibular izquierdo con p3-m2 (Fig. 3.7-8), MLP 92-X-10-1,; fragmento mandibular derecho con $\mathrm{m} 2$, MPEFPV 4962; fragmento mandibular derecho con $\mathrm{m} 1$, MPEF-PV 4989; $\mathrm{m} 1$ derecho, MPEF-PV 4741; m1 izquierdo, MPEFPV 4931; m1 izquierdo, MPEF-PV 4940; m1 izquierdo, MPEF-PV 5284; $\mathrm{m} 2$ izquierdo, MPEF-PV 4739; $\mathrm{m} 2$ izquierdo, MPEF-PV 4934; m2 izquierdo, MPEF-PV 4943; m2 izquierdo, MPEF-PV 4961; m3 derecho, MPEF-PV 4932; m3 derecho, MPEF-PV 4938; m3 izquierdo, MPEF-PV 4963; m4 derecho, MPEF-PV 4930; $\mathrm{m} 4$ derecho, MPEF-PV 5281; fragmento de maxilar derecho con M2-M3 (Fig. 3.9-10), MPEF-PV 5661; fragmento maxilar derecho con M3-M4, MPEF-PV 6026; M1 derecho, MPEF-PV 4737; M1 derecho, MPEF-PV 4919; M1 derecho, MPEF-PV 4920; M1 derecho, MPEF-PV 4971; M1 izquierdo, MPEF-PV 4975; M2 izquierdo, MPEF-PV 4736; M2 derecho, MPEF-PV 5282; M2 izquierdo, MPEF-PV 5283; M3 derecho, MPEF-PV 4918; M3 izquierdo, MPEF-PV 4922.

Procedencia geográfica y estratigráfica. Gran Barranca, Puesto Almendra (Departamento Sarmiento, Provincia

Figura 3. 1-6, Clenia minuscula, 1-2, MPEF-PV 6017, fragmento mandibular izquierdo con alvéolos de los p1-p3 y m4 y los m1-m3 completos en vistas oclusal y labial/ left mandibular fragment with $p 1-p 3$ and $m 4$ alveolus, and complete $m 1-m 3$ in occlusal and labial views, 3-4, MPEF-PV 4912, fragmento de maxilar izquierdo con P3-M1 en vistas oclusal y lingual/ left maxillary fragment with P3-M1 in occlusal and lingual views, 5-6, MPEF-PV 4974, M2 izquierdo en vistas oclusal y lingual/ left M2 in occlusal and lingual views; 7-10, Oligobiotherium divisum, 7-8, MLP 92-X-10-15, fragmento mandibular izquierdo con p3-m2 en vistas oclusal y labial/ left mandibular fragment with $p 3-m 2$ in occlusal and labial views, 9-10, MPEF-PV 5661, fragmento de maxilar derecho con M2-M3 en vistas oclusal y oclusolingual/ right maxillary fragment with M2-M3 in occlusal and occluso-lingual views; 11-15, Eomicrobiotherium mikerum, 11, MPEF-PV 5658, fragmento mandibular derecho con raíces de los p2-p3, m1 entero, raíces del m2 y $\mathrm{m} 3-\mathrm{m} 4$ enteros en vista oclusal/ right mandibular fragment with $p 2-p 3$ roots, complete $m 1, m 2$ roots, and complete $m 3-m 4$ in occlusal view; 12-13, MPEF-PV 4732, M1 derecho en vistas oclusal (12) y lingual (13)/ right M1 in occlusal (12) and lingual (13) views; 14-15, MPEF-PV 4972, M2 derecho en vistas oclusal y lingual/ right M2 in occlusal and lingual views; 16-17, Microbiotherium sp., MLP 77-VI-13-13, fragmento mandibular derecho con p3-m4 en vistas oclusal y labial/ right mandibular fragment with p3-m4 in occlusal and labial views; 18, MPEF-PV 5302, fragmento mandibular izquierdo con $\mathrm{m} 2$ y alvéolos del $\mathrm{m} 3$ en vista oclusal/ left mandibular fragment with complete $\mathrm{m} 2$ and $\mathrm{m} 3$ alveolus in occlusal view. Escala/ scale= $1 \mathrm{~mm}$. 
$(1)$

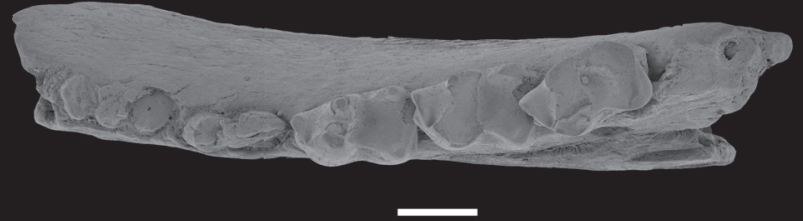

2

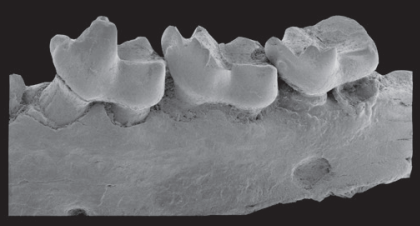

7
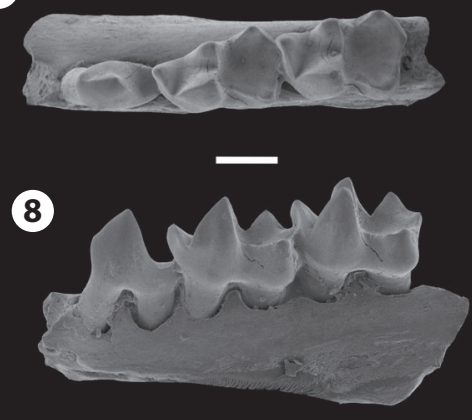

(11)

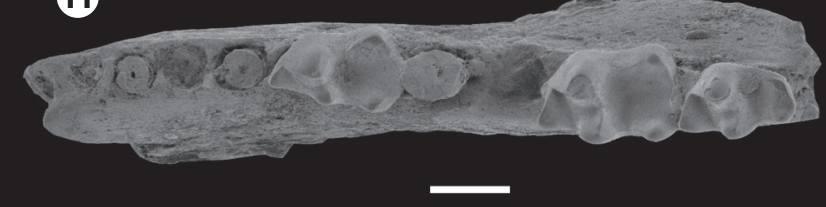

16
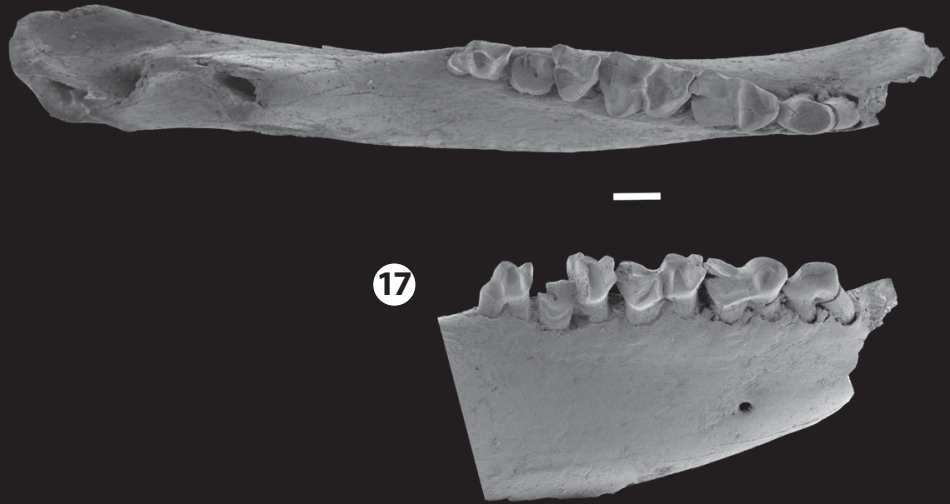

3

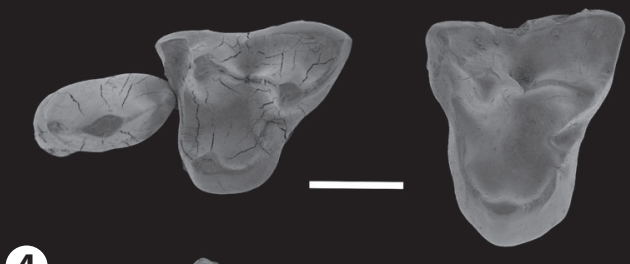

4

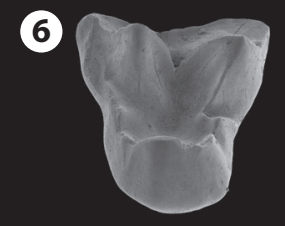

9

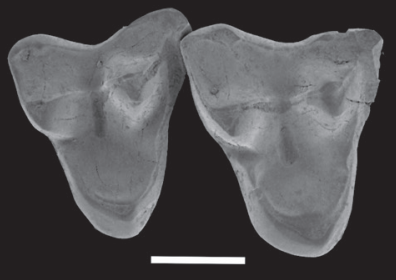

10

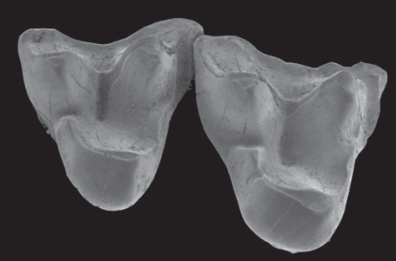

(12)

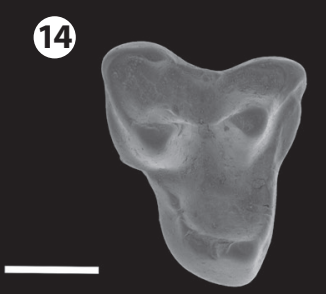

13 (15)

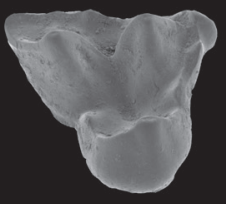

18
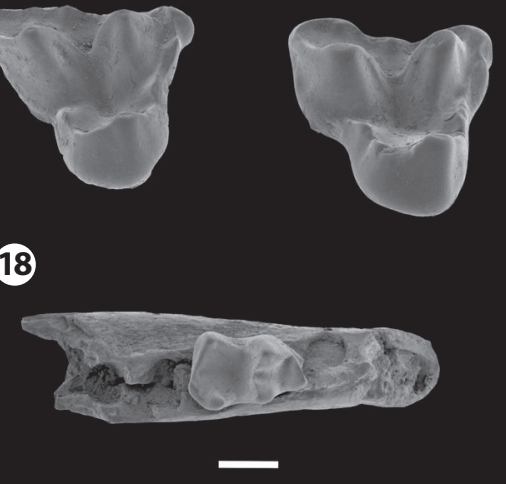
de Chubut, Argentina). Formación Sarmiento, Miembro Colhue Huapi. Mioceno temprano (Edad mamífero Colhuehuapense). Los ejemplares MPEF-PV 4741, MPEFPV 4739, MPEF-PV 4737 y MPEF-PV 4736 provienen del "nivel C" ; los ejemplares MPEF-PV 4943, MPEFPV 4940, MPEF-PV 4938, MPEF-PV 4934, MPEF-PV 4932, MPEF-PV 4931, MPEF-PV 4930, MPEF-PV 4922, MPEF-PV 4920, MPEF-PV 4919 y MPEF-PV 4918 proceden del "nivel C Gris"; los ejemplares MPEF-PV 4989, MPEF-PV 4975, MPEF-PV 4971 proceden del "nivel B", los ejemplares MPEF-PV 5284, MPEF-PV 5283 y MPEFPV 5282 proceden del nivel "Mono Oeste Superficial" y los ejemplares MPEF-PV 4961, MPEF-PV 4962 y MPEF-PV 4963 de "Mono Este Superficial". El resto de los ejemplares aquí referidos no tiene una procedencia específica más allá de su exhumación en el Miembro Colhue Huapi.

Medidas. Se detallan en el Apéndice 2 (Archivo Suplementario en línea).

Diagnosis enmendada. Oligobiotherium divisum se diferencia de los restantes Microbiotheria por la siguiente combinación de caracteres: $\mathrm{m} 4$ reducido en relación al $\mathrm{m} 3$, canino inferior de implantación subvertical; rama horizontal mandibular baja, sin diferencia de altura entre los planos alveolares de premolares y molares; p2 alineado con la serie p3-m4; paracónidos de los $\mathrm{m} 1-\mathrm{m} 2$ sin compresión anteroposterior; protocónido del $\mathrm{m} 1$ inclinado lingualmente y vertical en el $\mathrm{m} 2$; postcrístida de los $\mathrm{m} 1-\mathrm{m} 2$ perpendicular al eje anteroposterior de los molares y metacónido bien retrasado respecto del protocónido en los $\mathrm{m} 1-\mathrm{m} 2$.

Emended diagnosis. Oligobiotherium divisum differs from other Microbiotheria by the following combination of features: $m 4$ reduced in relation to $m 3$, lower canine subvertical, horizontal ramus low; the alveolar edge is even at the p3-m1 boundary (i.e., alveolar plane without height difference between premolars and molars); $p 2$ aligned with $p 3-m 4$ series; paraconids in m1-m2 not compressed antero-posteriorly; protoconid in $m 1$ lingually bended, while that of $m 2$ vertical; postcristid of $m 1-m 2$ transverse to the molar axis; metaconid posterior to the protoconid in $m 1-m 2$.

Descripción. El dentario más completo de $O$. divisum es el MLP 83-III-I-204a; presenta los alvéolos de los i2-i4 subiguales entre sí, excepto el más anterior que, si bien mantiene el mismo ancho, es algo más corto que los posteriores. A juzgar por su alvéolo, el canino era de tamaño apenas moderado, de sección subcircular y estaba implantado verticalmente. El p1 se implanta algo oblicuamente en la serie yugal al igual que el $\mathrm{p} 2$, en menor medida. Las raíces del p3 se disponen en forma paralela al eje dentario. El p3 es el mayor de los premolares. Según se aprecia en el borde ventral mandibular por debajo del canino, la rama horizontal mandibular era relativamente baja. El foramen mentoniano anterior se ubica por debajo de la raíz anterior del p1; un segundo foramen, algo menor, aparece por debajo de la raíz posterior del $\mathrm{m} 1$. El p3 es de sección suboval y está bien comprimido en sentido labiolingual, presenta una única cúspide central de la cual parten dos crestas cortantes: una anterior $y$ una posterior. La cresta posterior no corre exactamente por la mitad de la ladera posterior del diente, sino que lo hace algo labialmente a ésta, delimitando en la base una pequeńa cuenca sin cúspide aparente. Los molares inferiores son alargados y de aspecto relativamente grácil. Los $\mathrm{m} 1-\mathrm{m} 3$ se caracterizan por la escasa compresión anteroposterior del paracónido, el carácter saliente del hipocónido y por presentar el metacónido del $\mathrm{m} 1$ relativamente pequeño y algo desplazado posteriormente. La reducción del $\mathrm{m} 4$ es menos notoria que en Microbiotherium. Como en otros microbiotéridos, los cíngulos anterobasales son vestigiales o ausentes.

Varios especímenes pertenecientes a la dentición superior se refieren aquí a Oligobiotherium divisum. Todos concuerdan en tamaño con los dientes inferiores asignados a $O$. divisum, así como también con la morfología inferida a partir de la dentición inferior. Los rasgos más salientes de la dentición superior son: el largo de los dientes disminuye visiblemente del M1 al M3; si bien el M4 está reducido con respecto al M3, dicha reducción es menor que en $M$. tehuelchum y mucho menor que en $M$. patagonicum y Dromiciops. Los protoconos de los M1-M3 son relativamente anchos y, comparados con $M$. tehuelchum, sus cúspides son menos excéntricas. En el M2 es posible distinguir las cuatro cúspides estilares: StA grande y ocupando toda la esquina parastilar del diente; $\mathrm{StB}$ muy pequeña y labial al paracono; $\mathrm{StC}$ comprimida labiolingualmente, dividida en dos cúspulas de menor tamaño que la StB; posterior a esta cúspide se desarrolla una cresta que llega casi hasta la base de la $\mathrm{StD}$; y $\mathrm{StD}$ poco comprimida labiolingualmente y con la base más grande que las dos anteriores. Como en otros microbiotéridos, la preparacrista se dirige a la StA, el paracono y el metacono son subiguales en altura, la postmetacrista se reduce progresivamente del M1 al M3 (estando en los M3 orientada más perpendicularmente que en los dientes anteriores) y el paracónulo y el metacónulo están poco desarrollados (si bien el metacónulo es algo más grande que el paracónulo). En el M3, las cúspides estilares son menos visibles, desarrollándose un esbozo de repisa o cresta muy baja casi ininterrumpida a lo largo de la cara labial del diente. En el M4, el metacono está presente 
y es más desarrollado que en otros microbiotéridos, lo cual le otorga al diente un aspecto subtriangular. En los M1-M3 los ectoflexos son más pronunciados que en M. tehuelchum, alcanzando un desarrollo similar a los de Dromiciops.

Concordantemente con el carácter relativamente saliente de los hipocónidos de los molares inferiores, el alargamiento labiolingual del protocono en los M1-M3 sugiere un mayor componente masticatorio ectental de Oligobiohterium con respecto a formas de tamańo similar como Clenia, Microbiotherium o Dromiciops.

Comentarios. Marshall (1982, p. 25-26) resumió consideraciones previas de Reig (1955) sobre Oligobiotherium divisum y concordó con él en sinonimizar a $O$. divisum, Clenia minuscula y Microbiotherium hernandezi en una única especie, $M$. divisum. Nosotros concordamos en la identidad específica de $M$. hernandezi y $O$. divisum, no así en su coespecificidad con Clenia minuscula (ver más arriba). A pesar de su carácter sumamente fragmentario, el holotipo de $O$. divisum (MACN-A 52-374) comparte con el holotipo de $M$. hernandezi (AMNH 29664) tres de sus rasgos distintivos: hipocónidos salientes, paracónidos no comprimidos anteroposteriormente y $\mathrm{m} 4$ reducido pero no vestigial con respecto al m3. Los ejemplares aquí referidos a $O$. divisum también concuerdan con ambos holotipos en estos y otros rasgos visibles en el AMNH 29664: moderado desarrollo del canino, tamaño relativo e implantación de los premolares, compresión lateral del p3, metacónido (sobre todo en el m1) bien desplazado posteriormente. En síntesis, $M$. hernandezi es un sinónimo junior de Oligobiotherium divisum.

\section{Género Eomicrobiotherium Marshall, 1982}

1964. ?Coona Simpson, p. 7; Simpson, 1967, p. 7.

1977. Microbiotherium Del Corro, p. 32.

Especie tipo. Eomicrobiotherium gaudryi (Simpson, 1964).

Especies incluidas. La especie tipo, E. matutinum Goin, Abello y Chornogubsky, 2010 y E. mykerum sp. nov.

Distribución. Eoceno tardío (Edad mamífero Casamayorense)-Mioceno temprano (Edad mamífero Colhuehuapense); Patagonia central.

Diagnosis enmendada. Eomicrobiotherium se diferencia de los restantes géneros de Microbiotheria por la siguiente combinación de caracteres: postcrístida de los m1-m2 oblicua respecto del eje anteroposterior de los molares; plano alveolar continuo en el límite p3-m1; rama mandibular horizontal baja; metacónido bien retrasado respecto del protocónido en los $\mathrm{m} 1-\mathrm{m} 2$; y paracónido de los $\mathrm{m} 1-\mathrm{m} 2$ no comprimido anteroposteriormente.
Emended diagnosis. Eomicrobiotherium differs from other Microbiotheria in the following combination of features: postcristid of $m 1-m 2$ obliquely set with respect to the dental axis; alveolar edge even at the p3-m1 boundary; low horizontal ramus; metaconid quite posteriorly placed with respect to the protoconid in m1-m2; and paraconid of m1-m2 not compressed anteroposteriorly.

\section{Eomicrobiotherium mykerum sp. nov.}

Figura 3.11-15

Etimología. Mykerum, del griego mykeros, "almendra", por Puesto Almendra (Barranca Sur del Lago Colhue Huapi), localidad tipo de la nueva especie.

Holotipo. Fragmento mandibular derecho con raíces de los $\mathrm{p} 2-\mathrm{p} 3, \mathrm{~m} 1$ completo, raíces del $\mathrm{m} 2$ y $\mathrm{m} 3-\mathrm{m} 4$ completos, MPEF-PV 5658 (Fig. 3.11).

Material referido. Fragmento mandibular izquierdo con las raíces de los m2-m3 y el m4 completo, MPEF-PV 5292; m1 izquierdo, MPEF-PV 4944; m1 derecho, MPEF-PV 4964; $\mathrm{m} 1$ derecho MPEF-PV 4993; m2 izquierdo, MPEFPV 4734; m2 izquierdo, MPEF-PV 4939; m2 izquierdo, MPEF-PV 4959; m2 izquierdo, MPEF-PV 4990; $\mathrm{m} 2$ derecho, MPEF-PV 6024; m3 izquierdo, MPEF-PV 4729; m3 izquierdo, MPEF-PV 4733; m3 izquierdo, MPEF-PV 4960; m4 izquierdo, MPEF-PV 4986; M2 izquierdo, MPEF-PV 4731; M1 derecho, MPEF-PV 4732 (Fig. 3.12-13); M2 derecho, MPEF-PV 4917; M2 derecho, MPEF-PV 4972 (Fig. 3.14-15); M3 derecho, MPEF-PV 4973; M3 izquierdo, MPEF-PV 6027; M4 izquierdo MPEF-PV 4730.

Procedencia geográfica y estratigráfica. El holotipo y los ejemplares referidos (excepto el MPEF-PV 5292) proceden de la localidad Barranca Sur del lago Colhue Huapi (Departamento Sarmiento, Provincia de Chubut, Argentina). Formación Sarmiento, Miembro Colhue Huapi. Mioceno temprano (Edad mamífero Colhuehuapense). El ejemplar MPEFPV 5292 procede de la localidad de Loma Blanca (Gaiman, Provincia de Chubut). Formación Sarmiento, Miembro Trelew. Mioceno temprano (Edad mamífero Colhuehuapense). Los ejemplares de la localidad Barranca Sur proceden de los siguientes niveles: "nivel C", ejemplares MPEF-PV 4733, MPEF-PV 4730, MPEF-PV 4732, MPEF-PV 4731, MPEFPV 4734 y MPEF-PV 4729; "nivel C Gris", ejemplares MPEF-PV 4944, MPEF-PV 4939 y MPEF-PV 4917; "nivel B”, ejemplares MPEF-PV 4993, MPEF-PV 4990, MPEFPV 4986, MPEF-PV 4973 y MPEF-PV 4972; "Mono Este Superficial”, ejemplares MPEF-PV 4964, MPEF-PV 4960 y MPEF-PV 4959. El resto de los ejemplares aquí referidos no 
tiene una procedencia específica más allá de su exhumación en el Miembro Colhue Huapi.

Medidas. Se detallan en el Apéndice 2 (Archivo Suplementario en línea).

Diagnosis. Eomicrobiotherium mykerum sp. nov. se diferencia de las restantes especies del género por su menor tamaño, el talónido del $\mathrm{m} 1$ proporcionalmente más ancho (i.e., el hipocónido es más saliente), la ubicación más central del hipoconúlido del $\mathrm{m} 1$ y la menor compresión anteroposterior del paracónido del m1. Difiere de E. matutinum por el menor desarrollo del entocónido, la mayor longitud relativa de la pre-entocrístida y la mayor gracilidad de los protoconos en los molares superiores.

Diagnosis. Eomicrobiotherium mykerum sp. nov. differs from other species of the genus by its smaller size; wider talonid of $m 1$ (i.e., the hypoconid is more projected labially); hypoconulid of $m 1$ more centrally placed; and less anteroposteriorly compressed paraconid in $m 1$. It differs from E. matutinum by a less developed entoconid, a longer pre-entocristid, and more gracile protocones in the upper molars.

Descripción. El holotipo es el ejemplar más completo conocido para esta nueva especie. El cuerpo mandibular es de altura moderada y la hilera de los dientes yugales se dispone en forma casi recta, estando apenas arqueada por delante del p2. El foramen mentoniano anterior es relativamente grande y se ubica entre p1 y p2; el foramen mentoniano posterior, más pequeño, lo hace por debajo de la raíz anterior del m1. A juzgar por los alvéolos preservados, el p3 era claramente más grande que el p2; como en otros microbiotéridos, la raíz anterior del p2 tiene un diámetro de aproximadamente la mitad del de la raíz posterior. En el m1, el cíngulo anterobasal está ausente, el protocónido es comparativamente muy grande, con su cúspide inclinada lingualmente; el metacónido se ubica claramente por detrás del protocónido; el talónido es muy amplio tanto por el carácter saliente del hipocónido como por la disposición más lingual del entocónido, por lo que ambas cúspides delimitan una cuenca amplia y relativamente poco profunda. Un carácter de E. mykerum sp. nov. compartido con "M." gallegosense es la posición casi central del hipoconúlido en el $\mathrm{m} 1$ (y en menor medida en el m2), ubicado sobre el borde posterior del talónido; en consecuencia, en vista oclusal el talónido tiene un aspecto romboidal. En E. mykerum sp. nov., el hipoconúlido está algo más diferenciado que en otros microbiotéridos, donde es una estructura reducida y relativamente plana. La pre-entocrístida es larga y recta y su dirección se corresponde con un eje que atraviesa las cúspides del paracónido y el entocónido.

El m2 MPEF-PV 6024 se diferencia de los m1 de modo similar a lo que ocurre entre los molares homólogos de $E$. gaudryi: el metacónido se implanta algo menos posteriormente que en los $\mathrm{m} 1$, aparece un vestigio de cíngulo anterobasal, el hipocónido y el entocónido son menos salientes, y el hipoconúlido está más próximo al entocónido. Todos estos rasgos están más acentuados en el $\mathrm{m} 3$ del holotipo.

El m4 del holotipo está claramente reducido con respecto al m3, si bien no alcanza la reducción extrema observada en Microbiotherium o Dromiciops. El metacónido está casi en línea con el protocónido y el paracónido está menos reducido que en los molares anteriores; el cíngulo anterobasal está más desarrollado que en el m3. El talónido está algo reducido (a modo de espolón posterior al trigónido); el hipocónido es claramente más bajo que el entocónido, por lo que la cuenca del talónido no es horizontal, sino que muestra un claro declive hacia la cara labial del diente. La diferencia de altura entre el hipocónido y el entocónido está presente sólo en formas tempranas como Mirandatherium, de modo apenas incipiente, y Marambiotherium glacialis Goin, Case, Woodburne, Vizcaíno y Reguero, 1999, con un declive extremo.

El contorno de los molares superiores no es simétrico en vista oclusal, dado que el protocono es levemente excéntrico, ubicándose casi a la misma altura que la esquina parastilar del diente. Adicionalmente, el protocono es algo más angosto que en otros microbiotéridos. En todos los molares, el paracono y el metacono son subiguales en altura y la preparacrista se dirige a la esquina parastilar. La centrocrista es baja. Como en otros microbiotéridos, la postmetacrista se vuelve más transversal al eje dentario del M1 al M3; la postmetacrista del M3 es algo más corta que la del M2 y la de éste es subigual a la del M1. Tanto el paracónulo como el metacónulo alcanzan un escaso desarrollo; la plataforma estilar es estrecha y no desarrolla el reborde labial de otros microbiotéridos. $\mathrm{La} \mathrm{StC}$ es claramente visible en el M2 y vestigial en el M3; la StB está ausente en el M1 y es vestigial o ausente en los M2-M3; la StD es visible sólo en el M2, siendo en este molar más alargada y más baja que la $\mathrm{StC}$. Al menos en los M1-M3, el cíngulo anterior no se une a la preprotocrista, sino que ésta termina en la base del paracónulo.

\section{Género Microbiotherium Ameghino, 1887}

Especie tipo. Microbiotherium patagonicum Ameghino, 1887.

Especies incluidas. La especie tipo, M. tehuelchum, M. acicula y $M$. praecursor.

Distribución. Oligoceno temprano-Mioceno temprano (edades mamífero Tinguiririquense, Colhuehuapense y Santacrucense); Patagonia central. 


\section{Microbiotherium sp.}

Figura 3.16-17

Material referido. Rama mandibular derecha con p3-m4 muy gastados, MLP 77-VI-13-13 (Fig. 3.16-17); fragmento de rama mandibular izquierda con $\mathrm{m} 2$ y alvéolos del $\mathrm{m} 3$, MPEF-PV 5302 (Fig. 3.18); m1 izquierdo, MPEF-PV 4941; m2 izquierdo, MPEF-PV 4728; m3 derecho, MPEFPV 4923; m2 izquierdo, MPEF-PV 4966; m2 izquierdo, MPEF-PV 4967; m2 izquierdo, MPEF-PV 4987; m2 derecho MPEF-PV 4988; m3 derecho, MPEF-PV 4991; m3 derecho, MPEF-PV 4992.

Procedencia geográfica y estratigráfica. Barranca Sur del lago Colhue Huapi (Departamento Sarmiento, Provincia de Chubut, Argentina). Formación Sarmiento, Miembro Colhue Huapi. Mioceno temprano (Edad mamífero Colhuehuapense). Los ejemplares MPEF-PV 4941 y MPEF-PV 4923 proceden del "nivel C Gris"; los ejemplares MPEF-PV 4991, MPEF-PV 4988, MPEF-PV 4987 y MPEF-PV 4992 proceden del "nivel B"; el ejemplar MPEF-PV 4728 procede del "nivel C"; los ejemplares MPEF-PV 4966 y MPEF-PV 4967 proceden de "Mono Este Superficial"; el ejemplar MLP 77-VI-13-13 no tiene una procedencia específica más allá de su exhumación en el Miembro Colhue Huapi. El ejemplar MPEF-PV 5302 procede de la localidad de Loma Blanca (Gaiman, Provincia de Chubut), Formación Sarmiento, Miembro Trelew. Mioceno temprano (Edad mamífero Colhuehuapense).

Medidas. Se detallan en el Apéndice 2 (Archivo Suplementario en línea).

Descripción y comentarios. El MLP 77-VI-13-13 es el ejemplar más completo de esta serie. La rama horizontal es alta, recta y robusta, arqueándose mesialmente por delante del p3. El p3 es muy similar al del género Microbiotherium; la raíz anterior se implanta en un punto más lingual que el extremo mesial de la corona; se aprecia un pequeño talón posterior en este diente, más reducido que el de $M$. tehuelchum y similar al de $M$. praecursor. La serie molar está muy desgastada, si bien puede apreciarse que, al menos en el m2, el metacónido está poco desplazado posteriormente con respecto al protocónido; al igual que en $M$. tehuelchum, los hipocónidos son moderadamente salientes; el m4 es comprimido labiolingualmente y está claramente reducido en relación al m3. A juzgar por las dimensiones dentarias, el ejemplar MLP 77-VI-13-13 consituye el microbiotérido más pequeño exhumado hasta ahora en niveles colhuehuapenses. La preservación del resto de los materiales referidos a Microbiotherium sp. no permite una determinación taxonómica más precisa.
Microbiotherimdae indet.

Material referido. Fragmentos mandibulares MPEF-PV 4727, MPEF-PV 5831, MPEF-PV 5866, MPEF-PV 4946, MPEF-PV 4947, MPEF-PV 4950, MPEF-PV 4970, MPEFPV 6018 y MPEF-PV 6019; premolares aislados MPEF-PV 6020 y MPEF-PV 6021; fragmentos de molares inferiores MPEF-PV 4724, MPEF-PV 4726, MPEF-PV 4904, MPEFPV 4924, MPEF-PV 4925, MPEF-PV 4926, MPEF-PV 4927, MPEF-PV 4928, MPEF-PV 4929, MPEF-PV 4936, MPEF-PV 4956, MPEF-PV 4958, MPEF-PV 4980, MPEFPV 4981, MPEF-PV 4983, MPEF-PV 4984, MPEF-PV 4985 y MPEF-PV 6025; molares superiores (completos o fragmentarios) MPEF-PV 4911, MPEF-PV 4725, MPEFPV 4978, MPEF-PV 4723, MPEF-PV 4722, MPEF-PV 4721, MPEF-PV 4720, MPEF-PV 4719, MPEF-PV 4718, MPEF-PV 4913, MPEF-PV 4979, MPEF-PV 4909, MPEFPV 4953, MPEF-PV 4921, MPEF-PV 4977, MPEF-PV 4906, MPEF-PV 4907, MPEF-PV 4908, MPEF-PV 4905, MPEF-PV 4954 y MPEF-PV 4910.

Procedencia geográfica y estratigráfica. Barranca Sur del lago Colhue Huapi (Departamento Sarmiento, Provincia de Chubut, Argentina). Formación Sarmiento, Miembro Colhue Huapi. Mioceno temprano (Edad mamífero Colhuehuapense).

Comentarios. Las dimensiones y el aspecto general de los cuerpos mandibulares sugieren que estos especímenes podrían ser asignados tanto a Clenia como a Oligobiotherium. Por su parte, los restos dentarios no permiten referir con seguridad estos materiales a taxón alguno de Microbiotheriidae.

Orden Polydolopimorphia Archer, 1984

Suborden Bonapartherifformes Pascual, 1980

Superfamilia Argyrolagoidea Ameghino, 1904

Familia Argyrolagidae Ameghino, 1904

Género Proargyrolagus Wolff, 1984

Especie tipo. Proargyrolagus bolivianus Wolff, 1984.

Especies incluidas. P. bolivianus y $P$. argentinus sp. nov.

Distribución. Oligoceno tardío-Mioceno temprano, América del Sur.

Comentarios. Sobre la pertenencia de los Argyrolagidae (y del resto de los Argyrolagoidea, i.e., Groeberidae y Patagonidae) a los Polydolopimorphia, véase Goin y Candela (2004).

\section{Proargyrolagus argentinus sp. nov.}

Figura 4.1-12

Etimología. Argentinus, en referencia a la República Argenti- 
na, país de origen de la totalidad de los materiales asignados a esta nueva especie.

Holotipo. M2 derecho, MPEF-PV 4711 (Fig. 4.9-10). Material referido. M1 derecho, MPEF-PV 4715; M1 derecho, MPEF-PV 4714 (Fig. 4.7-8); M1 derecho, MPEF-PV 4786; M2 derecho MPEF-PV 4781; M2 izquierdo MPEFPV 4547; M3 izquierdo, MPEF-PV 4713 (Fig. 4.11-12); M3 derecho, MPEF 4783-PV; M?4 derecho, MPEF-PV 4782; Mx izquierdo, MPEF-PV 4784; Mx izquierdo, MPEF-PV 4785; $\mathrm{m} 1$ izquierdo, MPEF-PV 4712 (Fig. 4.12); m2 izquierdo, MPEF-PV 4778 (Fig. 4.3-4); m2 izquierdo, MPEF-PV 4789; m2 derecho, MPEF-PV 4776; m3 izquierdo, MPEF-PV 4716; m3 derecho, MPEF-PV 4710 (Fig. 4.5-6); m3 derecho, MPEF-PV 4788; m3 derecho, MPEF-PV 4790; m4 derecho, MPEF-PV 4717; mx derecho, MPEF-PV 4780; $\mathrm{mx}$ izquierdo, MPEF-PV 4787; mx derecho, MPEF-PV 4775.

Procedencia geográfica y estratigráfica. Puesto Almendra, Gran Barranca (Barranca sur del Lago Colhue Huapi), Departamento Sarmiento, Provincia del Chubut, Argentina. Formación Sarmiento, Miembro Colhue Huapi. Mioceno temprano (Edad mamífero Colhuehuapense).

Medidas. Se detallan en el Apéndice 2 (Archivo suplementario en línea).

Diagnosis. Se diferencia de Proargyrolagus bolivianus por los siguientes rasgos: molares superiores e inferiores más comprimidos en sentido labiolingual, diámetro anteroposterior del trigónido de los $\mathrm{m} 2-\mathrm{m} 3$ proporcionalmente más largo, protocónido vestigial, M2-M3 con el ectoflexo menos profundo y la esquina parastilar menos desarrollada, M2 con el metacónulo más expandido lingualmente, M1 con el protocono menos expandido lingualmente y el paracono+StB más reducidos.

Diagnosis. Differs from Proargyrolagus bolivianus in the following features: upper and lower molars more labiolingually compressed; proportionally longer trigonid in m2-m3; protoconid vestigial; M2-M3 with shallower ectoflexus and less developed parastilar corner; metaconule of M2 more developed labiolingually; protocone of $M 1$ less developed lingually and with more reduced paracone + StB.
Descripción. Los ejemplares asignados a Proargyrolagus argentinus sp. nov. consisten en piezas dentarias aisladas, mostrando todas un buen grado de preservación. Todos los molares son protohipsodontes; esto es, son de corona alta y las raíces están cerradas en su extremo distal.

La morfología del m1 es claramente distinta de aquella de los m2-m3 en la conformación del trigónido. El molar está notablemente comprimido en sentido labiolingual y presenta un protocónido muy grande y prominente en su extremo anterior (i.e., la cara anterior del $\mathrm{m} 1$ no es plana como en el resto de los molares inferiores sino que adopta la forma de una quilla o vértice relativamente anguloso). Labial y basalmente al protocónido se ubica un pequeño ectostílido. Posterior y lingualmente al protocónido se aprecia una estructura de difícil homologación; si bien su borde dorsal es crestiforme, su pared anterior es redondeada. En tal sentido, podría constituir o bien un metacónido o bien la porción más anterior de la pre-entocrístida. En otros argirolágidos existe una estructura similar, aunque su aspecto de cúspide es más evidente, por lo que aquí se la homologa al metacónido. No existe cuenca del trígono; la pared posterior del protocónido no es vertical, sino que se orienta oblicuamente, hasta conectarse con el talónido. El talónido muestra una morfología menos derivada; es ancho y cóncavo y las tres cúspides que lo forman son claramente reconocibles: el entocónido, muy desarrollado y desplazado anteriormente; el hipoconúlido, bien comprimido anteroposteriormente; y el hipocónido, mucho más bajo que el entocónido. El entocónido es cónico, alto, algo comprimido en sentido anterolingual-posterolabial y muestra su cara interna o anterolingual levemente cóncava. El hipoconúlido es claramente distinguible como una cúspide; debido a su alto grado de compresión anteroposterior, su cara posterior es plana y forma parte de la misma cara posterior del diente.

A diferencia del $\mathrm{m} 1$, el $\mathrm{m} 2$ tiene el trigónido y el talónido más isodiamétricos tanto en largo como en ancho. Estas estructuras se disponen a modo de lóbulos anterior y posterior, separados por un profundo surco labial y otro lingual, mucho menos notorio. El trigónido, similar al del m1, muestra

Figura 4. 1-12, Proargyrolagus bolivianus, 1-2, MPEF-PV 4712, $\mathrm{m} 1$ izquierdo en vistas oclusal y labial/ left $m 1$ in occlusal and labial views; 3-4, MPEF-PV 4778, $\mathrm{m} 2$ izquierdo en vistas oclusal y labial/ left $m 2$ in occlusal and labial views; 5-6, MPEF-PV 4710, m3 derecho en vistas oclusal y labial/ right $m 3$ in occlusal and labial views; 7-8, MPEF-PV 4714, M1 derecho en vistas oclusal y lingual/ right M1 in occlusal and lingual views; 9-10, MPEFPV 4711, M2 derecho en vistas oclusal y lingual/ right M2 derecho in occlusal and lingual views; 11-12, MEF-PV 4713, M3 izquierdo en vistas oclusal y lingual/ left M3 in occlusal and lingual views; 13-19, Anargyrolagus primus, 13, MPEF-PV 5474, fragmento mandibular izquierdo con los $\mathrm{m} 1$-m4 en vista oclusal/ left mandibular fragment with m1-m4 in occlusal view; 14-16, MPEF-PV 5291, fragmento mandibular izquierdo con los i1-m1 en vistas oclusal, labial y vista radiográfica lateral/ left mandibular fragment with i1-m1 in occlusal and labial views, and lateral radiographic view; 17-19, MPEF-PV 5299, fragmento mandibular izquierdo con el i1 y los p3-m4 en vistas oclusal y labial y vista radiográfica lateral/ left mandibular fragment with i1 and p3-m4 in occlusal, labial, and lateral radiographic views. Escala/ scale $=1 \mathrm{~mm}$. 


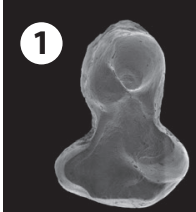

3

$(4)$

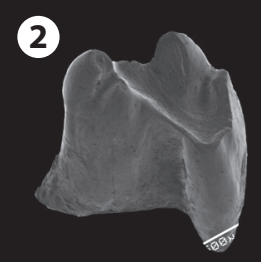

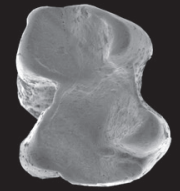

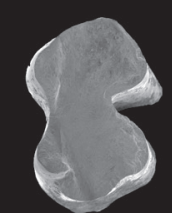

6

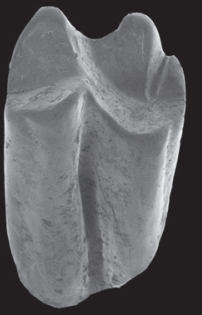

7

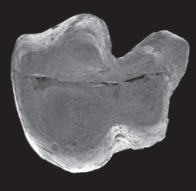

8

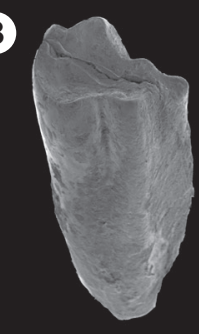

9

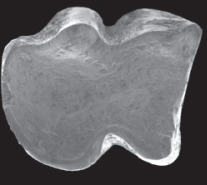

10

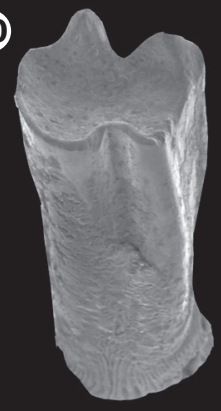

(11)

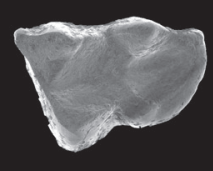

(12)

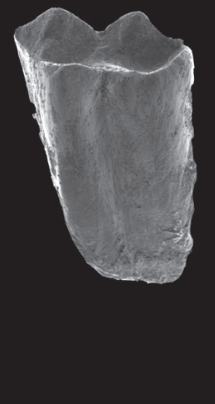

13
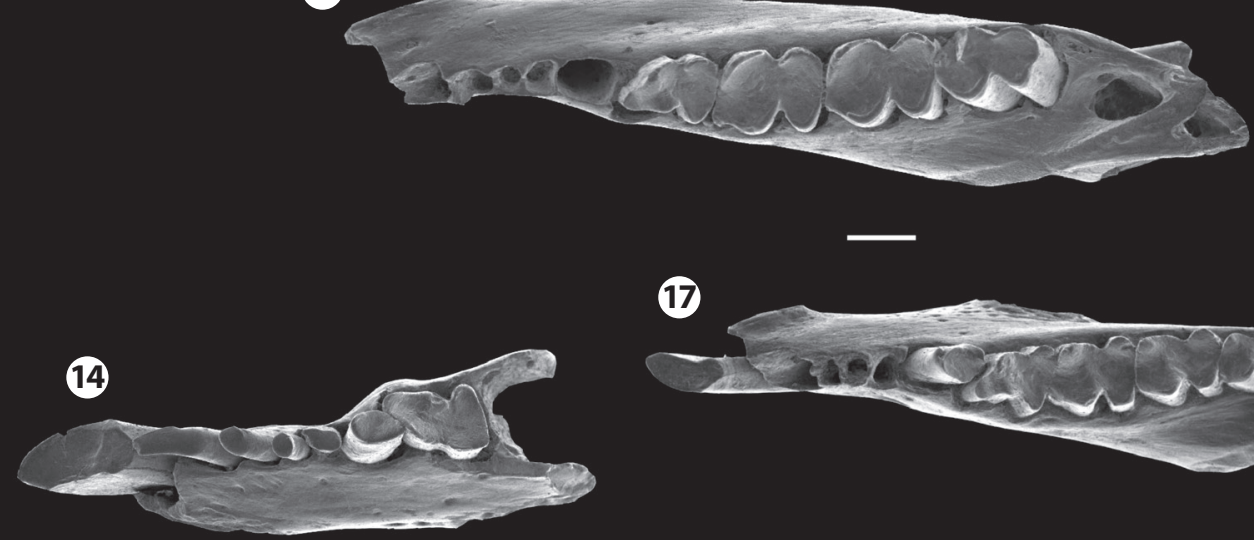

\section{7}

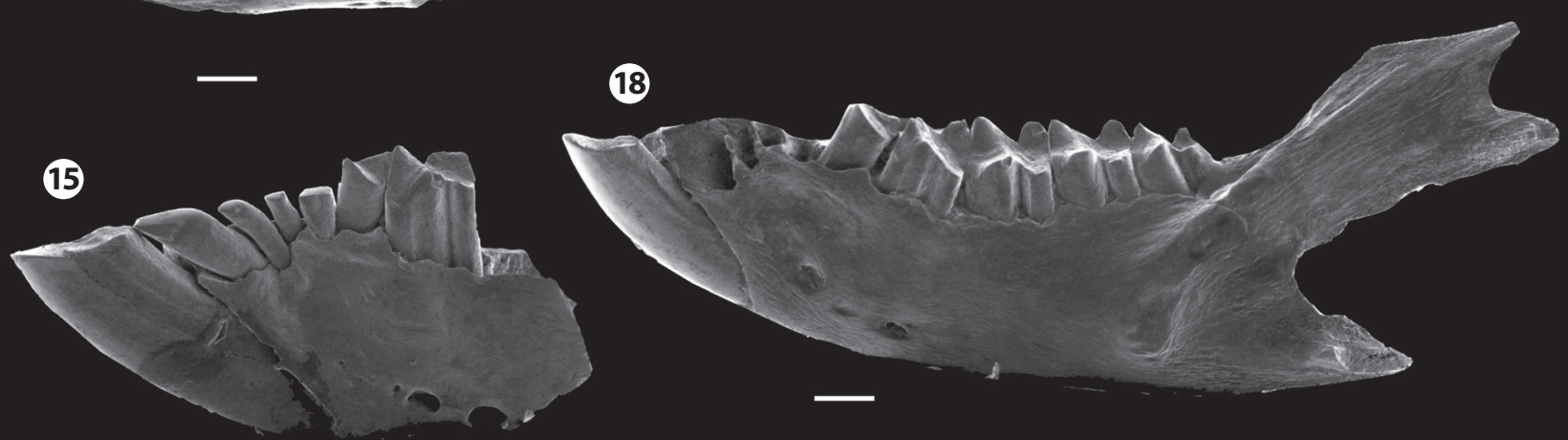

16

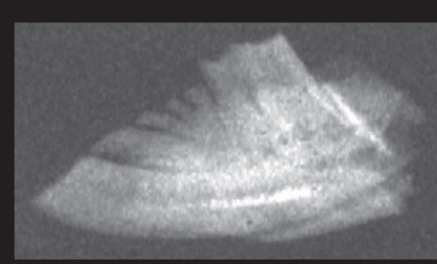

19

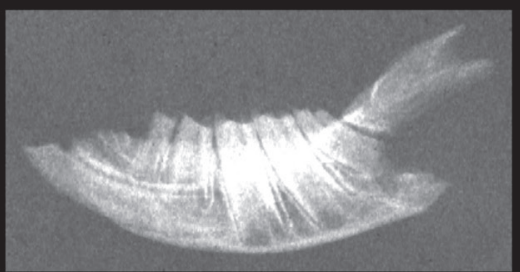


su cara anterior con una quilla que contribuye a aumentar el diámetro anteroposterior del trigónido y lo distingue claramente de $P$. bolivianus. Al igual que en la especie tipo, el $\mathrm{m} 2$ presenta un talónido proporcionalmente más largo que el trigónido, relación que se invierte en el m3. En vista oclusal, el metacónido y, en menor medida, el entocónido están profundamente transformados, constituyendo lofos paralelos al eje dentario. Estas cúspides son altas, subiguales en altura y desarrollan amplias crestas anteriores y posteriores a modo de un lofo casi continuo. El ejemplar MPEF-PV 4778 tiene poco desgaste, por lo que se aprecia que el borde posterior del entocónido es redondeado, dándole un aspecto más típicamente cuspidado que el metacónido. Por el contrario, las cúspides labiales (ectostílido e hipocónido) son bajas y planas; posterolingualmente, se observa el hipoconúlido como una cúspide comprimida anteoposteriormente y ubicada inmediatamente por detrás del entocónido. El ejemplar MPEF-PV 4778 permite apreciar el protocónido vestigial, cúspide mucho más desarrollada en $P$. bolivianus. Por último, los extremos apical y radicular son más angostos labiolingualmente que la porción media del diente.

La morfología oclusal del $\mathrm{m} 3$ es similar a aquella del $\mathrm{m} 2$. En el ejemplar MPEF-PV 4710, se aprecia que el entocónido es apenas más reducido que en el m2. En el MPEF-PV 4716, las raíces están cerradas, poco individualizadas como tales, por lo que el diente adquiere un aspecto prismático, con su extremo radicular más ahusado y el apical más ancho. Una fina capa de cemento cubre completamente la mitad radicular, así como también partes de las caras anterior y posterior del diente y del surco lingual. Con variantes, este rasgo se repite en otros molares de distintos argirolágidos. En vista posterior, se aprecia que la cara lingual del diente es levemente convexa y la labial es cóncava.

El m4 se caracteriza por la marcada reducción del talónido en relación al trigónido, siendo ambos subiguales en largo. Este molar está reducido en relación a los m2-m3 y la altura de su corona es menor. El metacónido es la cúspide más alta, comprimida labiolingualmente a modo de lofo. Anteriormente en el trigónido, a la altura del contacto con el m3, la capa de esmalte se adelgaza.

El M1 MPEF-PV 4714 presenta un escaso grado de desgaste y se puede apreciar la mayor altura de las cúspides labiales. Al igual que en $P$. bolivianus, este molar presenta un profundo ectoflexo (menos notorio hacia el ápice de la corona), delimitando dos sectores labiales. $\mathrm{El}$ anterior es más reducido que el posterior e incluye a la $\mathrm{StB}+$ paracono muy reducida y a la esquina parastilar del diente (más baja que la
StB y de aspecto cuspidado). El sector posterior comprende la $\mathrm{StD}+$ metacono; esta cúspide es de mayor tamaño que la $\mathrm{StB}+$ paracono y presenta una cresta corta que termina en la esquina metastilar del diente, de aspecto cuspidado (?StE). El protocono es más pequeño y está menos expandido lingualmente en comparación al metacónulo, por lo que el diente es más angosto anterior que posteriormente. El MPEF-PV 4715 presenta un mayor grado de desgaste, lo que explica algunas diferencias entre ambos M1; la cara oclusal es más grande, rasgo entendible debido a que el diente es de aspecto fusiforme $y$, por lo tanto, los sucesivos planos de desgaste muestran, hasta cierto punto, una mayor área oclusal. El ectoflexo es más profundo que en el MPEF-PV 4714. Lo inverso ocurre con el surco lingual (o entoflexo) que separa al protocono del metacónulo, siendo menos profundo en el MPEF-PV 4715. Los ejemplares MPEF-PV 4715 y MPEFPV 4786 tienen tres raíces: anterolabial, posterolabial y lingual.

A diferencia del M1, el ectoflexo de los M2-M3 es poco profundo en relación al entoflexo. La cara anterior del M2 es plana en casi toda su extensión y oblicua respecto al eje dentario. Por su parte, la cara posterior del diente (cresta postmetaconular) es redondeada. Labialmente, se aprecian dos cúspides, $\mathrm{StB}+$ paracono y $\mathrm{StD}+$ metacono, cada una con una cresta anterior y otra posterior, paralelas al eje dentario; la cresta anterior de la StB+paracono termina en la esquina parastilar del diente, mientras que la cresta posterior de $\mathrm{StD}+$ metacono lo hace en la esquina metastilar. Al igual que en el M1, el metacónulo es mucho más amplio y de contorno más redondeado que el protocono, pero esta cúspide está tan expandida lingualmente como el metacónulo, dando una sección más cuadrangular que en el M1.

El M3 está claramente más comprimido en sentido labiolingual que el M2, por lo que es relativamente más alargado; las esquinas parastilar y metastilar están más expandidas hacia delante y atrás, respectivamente, de modo que la sección del M3 es más trapezoidal que cuadrangular. A diferencia de los M1-M2, la StB+paracono es relativamente grande, siendo algo más alta que la $\mathrm{StD}+$ metacono. Ambas cúspides están unidas entre sí por crestas descendentes paralelas al eje dentario. Además, emiten crestas hacia delante (la $\mathrm{StB}+$ paracono) y hacia atrás (la $\mathrm{StD}+$ metacono) que se relacionan con las esquinas parastilar y metastilar, respectivamente. El metacónulo es más amplio que el protocono, pero menos saliente lingualmente. El ectoflexo está mucho menos desarrollado que en el M2 y es apenas distinguible. El 
protocono tiene sus caras anterolingual y posterolingual más planas, por lo que en vista oclusal es de aspecto más triangular que en los M1-M2.

El ejemplar MPEF-PV 4782 es asignado tentativamente a un M4. El molar es menor que el M3 y su mitad posterior está muy comprimida en sentido labiolingual. El protocono, cuya arista lingual es aguda, es mucho más saliente que el metacónulo. La cara anterior constituye la parte más elevada de la corona y no se orienta perpendicularmente al eje dentario, sino que se dirige posterolabialmente. Al igual que en el M3, el ectoflexo está muy poco desarrollado.

Comentarios. La estructura cuspidada de los molares inferiores (menos notoria en los superiores) y la presencia de raíces cerradas en todos los molares confirman la pertenencia de los materiales estudiados al género Proargyrolagus, previamente conocido sólo para el Oligoceno tardío (Edad mamífero Deseadense) de Bolivia. La aparente restricción de la capa de esmalte en la cara posterior de los molares inferiores, el trigónido y el talónido subiguales y el surco labial poco desarrollado son otros rasgos coincidentes con Proargyrolagus.

Todos los ejemplares asignados a Proargyrolagus argentinus sp. nov. provienen de la Barranca Sur del Lago Colhue-Huapi, contrastando con su ausencia en la localidad de Gaiman, que brindó numerosos restos de Anargyrolagus. Posiblemente, estas diferencias taxonómicas entre ambas localidades obedezcan a razones climático-ambientales, con una mayor proporción de tipos euhipsodontes en el área de Gaiman (Vucetich et al., 2010).

Proargyrolagus argentinus sp. nov. es similar a $P$. bolivianus, el argirolágido más antiguo hasta ahora conocido. Proargyrolagus difiere de los restantes argirolágidos conocidos en que los molares son de raíz cerrada y, en los ejemplares no desgastados, persisten cúspides bien desarrolladas, incluyendo el hipoconúlido de los molares inferiores. Otros rasgos plesiomorfos en el contexto de esta familia son la escasa altura de la rama mandibular, su fórmula dentaria relativamente generalizada, la ausencia de un foramen retromolar ("canal retrodentario", o retrodental canal en Hoffstetter y Villarroel, 1974; Sánchez-Villagra et al., 2000), la caja craneana poco globosa y las órbitas relativamente pequeñas (Sánchez-Villagra y Kay, 1997).

Género Anargyrolagus Carlini, Pascual y Goin, 2007 Especie tipo. Anargyrolagus primus Carlini, Pascual y Goin, 2007. Especies incluidas. La especie tipo solamente.

Distribución. Mioceno temprano de Patagonia.
Anargyrolagus primus Carlini, Pascual y Goin, 2007

Figuras $1.5,9$ y $4.13-19$

Holotipo. MACN-Ch 1305, fragmento de maxilar derecho con P3-M2, alvéolos de los C-P2 y parte anterior de los alvéolos del M3; fragmento del septo que separa las fenestras incisiva y maxilar, y parte de la raíz maxilar del arco cigomático. Material referido. Además de los ejemplares incluidos por Carlini et al. (2007), se asignan los siguientes: MPEF-PV 5102, fragmento mandibular derecho con el i1 y los m1m3; MPEF-PV 5103, fragmento mandibular derecho con el i1 y los m1-m2; MPEF-PV 5291, fragmento mandibular izquierdo con los i1-m1 (Fig. 4.14-16); MPEF-PV 5298, fragmento mandibular izquierdo con los i1, p1 y los p3m4; MPEF-PV 5299, fragmento mandibular izquierdo con el i1 y los p3-m4 (Fig. 4.17-19); MPEF-PV 5306a, fragmento mandibular izquierdo con el i1 y los m1-m3; MPEFPV 5473, fragmento mandibular derecho con los m3-m4; MPEF-PV 5474, fragmento mandibular izquierdo con los m1-m4 (Fig. 4.13); MPEF-PV 5295, fragmento mandibular izquierdo con los m2-m4; MPEF-PV 5286, m2 izquierdo; MPEF-PV 5300, m3 izquierdo; MPEF-PV 5306b, m2 derecho; MPEF-PV 5475, m2 derecho.

Procedencia geográfica y estratigráfica. Loma Blanca, Parque Paleontológico de Bryn Gwyn, sobre el margen sur del Río Chubut a la altura de Gaiman, provincia del Chubut, Argentina. Unidad ¿superior? del Miembro Trelew, Formación Sarmiento (véase Pascual y Carlini, 1987, p. 103); Mioceno temprano (Edad mamífero Colhuehuapense).

Medidas. Se detallan en el Apéndice 2 (material suplementario en línea).

Diagnosis enmendada. Anargyrolagus primus difiere de los restantes argirolágidos por la siguiente combinación de caracteres: fórmula dentaria I ?/2, C 1/1, P 3/3, M 4/4; molares euhipsodontes; molares superiores sin surco lingual; ectoflexo del M1 menos profundo que en Proargyrolagus; esquina parastilar de los M1-M2 menos desarrollada que en Proargyrolagus, pero más que en el resto de los argirolágidos; molares inferiores con el surco lingual más desarrollado que en Proargyrolagus y Microtragulus; comparado con Proargyrolagus, los trigónidos están mucho más desarrollados que los talónidos; los ectostílidos son más redondeados que en Hondalagus, Microtragulus y Argyrolagus; la cresta anterior del metacónido de los $\mathrm{m} 2-\mathrm{m} 3$ es más perpendicular al eje dentario que en Hondalagus, Microtragulus y Argyrolagus; el i2 es menos comprimido labiolingualmente que en Microtragulus y Argyrolagus; el p3 es subcircular en comparación con Argyrolagus y Microtragulus, en donde es subtriangular. 
Emended diagnosis. Anargyrolagus primus differs from other argyrolagids in the following combination of features: dental formula I ?/2, C 1/1, P 3/3, M 4/4; molars euhypsodont; upper molars without lingual groove; ectoflexus in $M 1$ shallower than in Proargyrolagus; parastylar corner of M1-M2 less developed than in Proargyrolagus, but more developed than in other argyrolagids; lower molars with the lingual groove deeper than in Microtragulus and Argyrolagus; compared with Proargyrolagus, trigonids are much more developed than talonids; ectostylids are more rounded than in Hondalagus, Microtragulus, and Argyrolagus; the anterior crest of the metaconid in $m 2-m 3$ is more transversally placed with respect to the dental axis than in Hondalagus, Microtragulus, and Argyrolagus; 22 is less labiolingually compressed than in Microtragulus and Argyrolagus; p3 is subcircular in section as compared with Microtragulus and Argyrolagus, in which it is subtriangular.

Descripción. Carlini et al. (2007) realizaron una descripción pormenorizada de los dientes superiores de este taxón, por lo que en este trabajo se describe mayormente la dentición inferior. De los nuevos restos, nueve son ramas mandibulares, lo que permite ampliar el conocimiento de la morfología mandibular y la serie dentaria inferior.

La altura y el contorno ventral del cuerpo mandibular varían entre los distintos ejemplares, de acuerdo a su carácter juvenil o adulto. En los primeros, son relativamente bajos y el borde ventral está curvado suavemente; los adultos presentan una altura relativa mayor y el borde ventral asciende abruptamente por delante del $\mathrm{m} 2$. Labial y anteriormente se observan dos o tres forámenes mentonianos; son de tamaño variable y se ubican entre la base del p3 y el límite m1-m2. Lingualmente, la sínfisis mandibular está pobremente delimitada y se prolonga desde el i1 hasta un punto ubicado por debajo del $\mathrm{m} 2$; ésta constituye una zona de gran rugosidad que presenta dorsalmente un reborde entre el i1 y el c. Exactamente por detrás del área sinfisaria se observa el extremo proximal del i1, el cual ha quedado expuesto debido a la rotura de la cara mandibular interna. Esta cara se encuentra perforada por numerosos forámenes de tamańo variable hasta el límite más posterior de la mandíbula. Hacia adelante, estos forámenes disminuyen en cantidad y se ubican entre la hilera dentaria y la parte porterior de la sínfisis mandibular.

El ejemplar MPEF-PV 5291 es el único que ha preservado la serie dentaria completa por delante del p3. El i1 muestra un progresivo aumento del ancho y del diámetro anteroposterior hacia el extremo proximal, de modo que sus dimensiones varían con el crecimiento y el desgaste. Su posición es oblicua al eje mandibular, por lo que el extremo proximal ocupa una posición lingual. El i2, a diferencia de su homólogo en Argyrolagus y Microtragulus, es de sección más circular y de menor tamaño que el i1; debido a su procumbencia, el extremo distal de la corona está en contacto con el extremo posterior de la corona del i1. El canino, columnar y procumbente, es de tamaño menor que el i2. El p1 es el menor de todos los dientes anteriores al $\mathrm{m} 1$; al igual que el canino, es columnar pero menos procumbente. Los p2-p3 son de implantación vertical; el p2 se caracteriza por su compresión labiolingual y su tamaño menor que el p3. A juzgar por las radiografías obtenidas de los ejemplares MPEF-PV 5291 y MPEF-PV 5299 (Fig. 4.16,19), el tipo de crecimiento euhipsodonte ocurriría en los i1-i2 y $\mathrm{p} 3$, mientras que el canino y los p1-p2 tendrían un tipo de crecimiento protohipsodonte (sensu Mones, 1982). Por otro lado, la serie molar muestra un crecimiento euhipsodonte, siendo todos los molares prismáticos y de corona alta. En el ejemplar MPEF-PV 5299 (Fig. 4.19), correspondiente a un individuo subadulto, los $\mathrm{m} 1-\mathrm{m} 4$ aumentan de tamaño desde la superficie oclusal hacia la base; esta diferencia es más acentuada en el $\mathrm{m} 4$, por lo que con el crecimiento este molar se torna proporcionalmente más grande que el m3. Esto explicaría la variación presente en los tamaños relativos de los m3-m4 entre los distintos especímenes estudiados. Un rasgo común a todos los molares es la constricción marcada entre el trigónido y el talónido, con surcos verticales lingual y labial bien desarrollados. El m1 es pequeño en relación a los m2-m3 y su trigónido es bastante comprimido comparado con el de otros argirolágidos (excepto Proargyrolagus bolivianus, en el que es aún proporcionalmente más angosto). Por su parte, los m2-m3 varían en tamańo relativo entre los distintos ejemplares, pero típicamente se diferencian en las proporciones del trigónido y del talónido —el $\mathrm{m} 2$ presenta un talónido más corto y ancho que el del m3-. Finalmente, los trigónidos de los m2-m4 se caracterizan por el ectostílido redondeado, presentando las caras anterior y posterior subiguales, y el metacónido con la cara anterior más perpendicular al eje dentario.

Comentarios. Hasta el momento, la serie antemolar de $A$. primus era desconocida, por lo que los nuevos ejemplares aportan valiosa información sobre la fórmula dentaria de esta especie. Si bien desde un punto de vista morfológico, debido a su aspecto simplificado, es difícil discernir entre dientes incisivos, caninos y premolares, se puede inferir la fórmula antemolar inferior a partir del conocimiento de la presencia de seis alvéolos y/o dientes antemolares inferiores y de tres loci premolares en la dentición superior (Carlini et al., 2007). 
Dada la información conjunta de las series dentarias superior e inferior, proponemos como fórmula dentaria más probable de $A$. primus: I?/2, C1/1, P3/3, M4/4.

Familia Patagoniddae Pascual y Carlini, 1984

Género Patagonia Pascual y Carlini 1987

Especie tipo. Patagonia peregrina Pascual y Carlini 1987

Especies incluidas. La especie tipo solamente.

Distribución. Mioceno temprano de Patagonia.

\section{Patagonia peregrina Pascual y Carlini, 1987}

Figura 5.1-3

Holotipo. Un fragmento de rama mandibular derecha con tres dientes yugales, la porción intra-alveolar del incisivo y el alvéolo del canino, MACN CH-869,

Material referido. Un fragmento mandibular derecho con los m1-m2 completos, MACN CH-864; fragmento mandibular derecho con los m1-m3, MACN CH-865; fragmento mandibular izquierdo con los m2-m3, MACN $\mathrm{CH}-866$; fragmento mandibular izquierdo con los $\mathrm{m} 1-\mathrm{m} 2$, MACN CH-867; fragmento mandibular derecho con los m1-m3, MACN CH-868; fragmento mandibular izquierdo con los m1-m2, MACN CH-870; fragmento mandibular derecho con los m2-m3, MACN CH-875; mandíbula derecha completa con el incisivo, el canino y los m1-m3, MLP 90-II-13-15a (Fig. 5.2-3); fragmento mandibular izquierdo con los m2-m3, MLP 90-II-13-15b; fragmento mandibular derecho con el incisivo y los m1-m2, MPEF-PV 4777; fragmento mandibular derecho con los m2-m3 y la porción proximal del incisivo, MPEF-PV 5296; fragmento de maxilar izquierdo con parte del paladar, la porción basal del arco cigomático y los M1-M3, MPEF-PV 5290 (Fig. 5.1).

Procedencia geográfica y estratigráfica. "Loma Blanca", Parque Paleontológico de Bryn Gwyn, sobre el margen sur del Río Chubut a la altura de Gaiman, provincia del Chubut, Argentina. Unidad ¿superior? del Miembro Trelew, Formación Sarmiento (véase Pascual y Carlini, 1987, p. 103); Mioceno temprano (Edad mamífero Colhuehuapense).

Medidas. Se detallan en el Apéndice 2 (Archivo suplementario en línea).

Diagnosis enmendada. Fórmula dentaria I?1/i1, C?1/?c1, $\mathrm{P}$ ?/p0, M3/m3; cuerpo mandibular corto y profundo, con la mitad posterior robusta y muy convexa labialmente; cresta masetérica fuerte, limitando una fosa masetérica de ubicación relativamente dorsal por detrás de dicha cresta; sínfisis mandibular subvertical, lisa, no fusionada; único incisivo inferior hipertrofiado, muy comprimido lateralmente, rodeado por esmalte y con el plano oclusal subvertical en su mitad anterior; su extremo proximal, de raíz abierta, extendido posteriormente hasta debajo del $\mathrm{m} 3$; ?canino inferior muy reducido, procumbente y de aspecto incisiviforme, separado de los molares por un fuerte diastema; molares superiores e inferiores euhipsodontes, de aspecto simple y tubular, de sección subcircular a subcuadrangular.

Emended diagnosis. Dental formula I?1/i1, C?1/?c1, P?O/ pO, M3/m3; short and deep horizontal ramus; with the posterior half convex and stout; strong masseteric crest bordering a masseteric fossa, which is dorsally placed posterior to the crest; unfused, subvertical symphysis; single lower incisor hyperthrophied, very compressed laterally, completelly surrounded by enamel, and with the occlusal plane subvertical on its anterior half; its proximal tip open-rooted and extended posteriorly up to a point below m3; lower ?canine very reduced, procumbent, and incisor-shaped; long diastema between the lower ?canine and molars; upper and lower molars euhypsodont, tube-shaped, subcircular to subquadrangular in section.

Descripción. El paladar carece de fenestras, si bien en su parte más anterior y ventral se aprecian unos pequeños forámenes por delante de los M1-M2, el más anterior de mayor tamaño. Estos forámenes constituyen las aberturas de finos conductos que corren perpendicularmente a la serie dentaria entre el M1 y el M2 y que luego se orientan más oblicuamente. Dorsalmente se pueden observar las raíces abiertas de los molares. En vista lateral, se aprecia una serie de forámenes que abren en distintos puntos de la cara labial. La base del arco cigomático se ubica a la altura del M1 y continúa por delante de éste en una superficie plana marcando el límite anterior de la serie molar.

La mandíbula es alta, aumentando progresivamente hacia atrás. La región posterior presenta lingualmente una fosa pterigoidea muy excavada que incluye, al menos, dos forámenes ventrales pequeños. La rama horizontal es labialmente más convexa en su mitad posterior. Existe un único foramen mentoniano ubicado cerca del borde ventral, labialmente al alvéolo del incisivo. El borde alveolar es recto a la altura de los molares; por delante, le sigue un diastema con el borde dorsal mandibular de aspecto crestado que se eleva hacia adelante, por lo que el plano alveolar del canino se ubica por encima del de la serie molar. En la superficie del diastema se observa un pequeño foramen que equidista del $\mathrm{m} 1 \mathrm{y}$ del canino. A este nivel, la mandíbula se hace claramente más angosta que en la región molar. Dorsalmente a la fosa pterigoidea, abre un foramen ovalado con su eje mayor en dirección aproximadamente anteroposterior. El tamaño mandibular del ejemplar MLP 90-II-13-15b es algo menor que el del holotipo. 
El incisivo inferior es procumbente y su curvatura hace que su tercio distal sea casi vertical. La porción intralveolar se orienta lingualmente en forma progresiva, de adelante hacia atrás, hasta un punto debajo del m3. En sección es

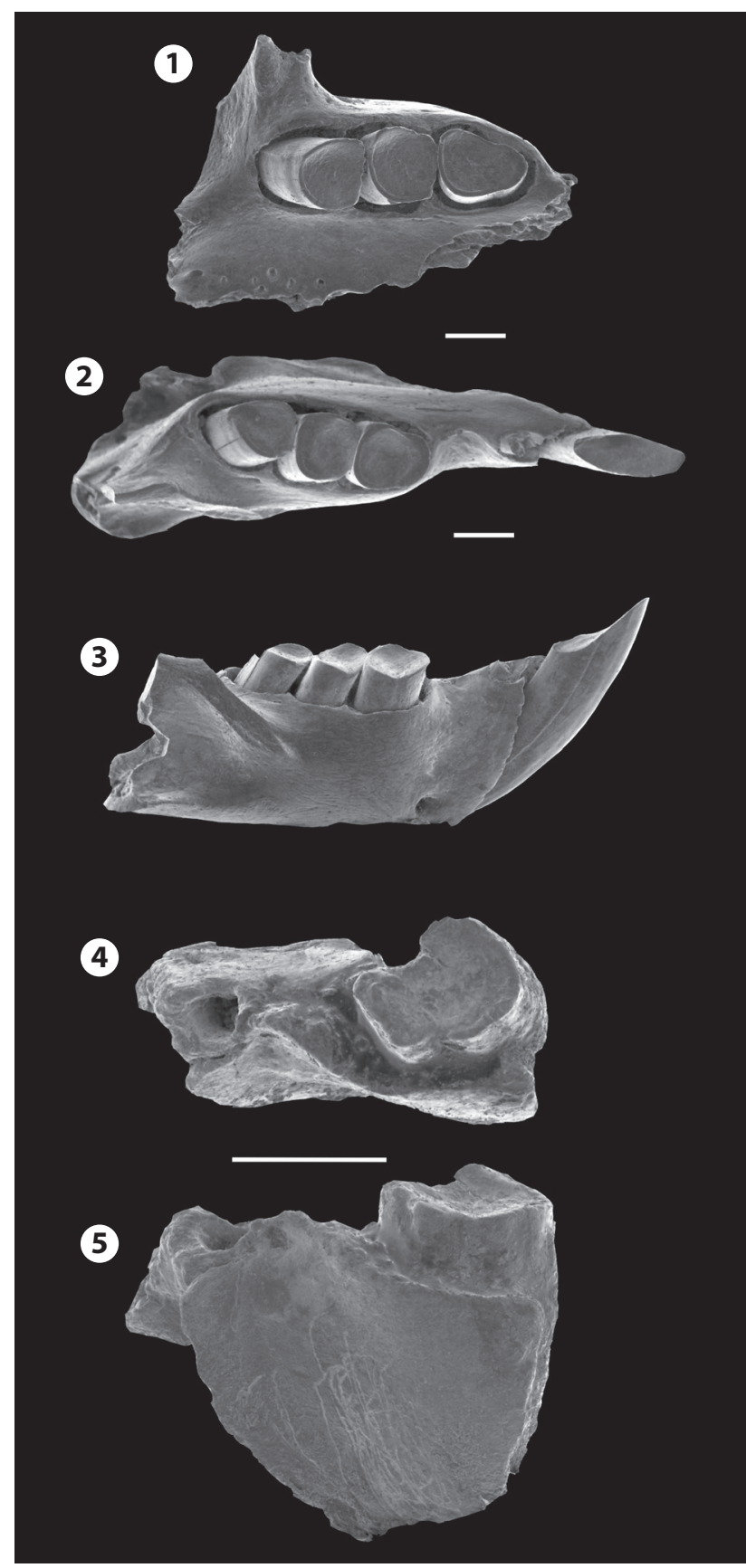

Figura 5. 1-3, Patagonia peregrina, 1, MPEF-PV 5290, fragmento maxilar izquierdo con los M1-M3 en vista oclusal/ left maxillary fragment with M1-M3 in occlusal view, 2-3, MLP 90-II-13-15a, fragmento mandibular derecho con incisivo, canino y $\mathrm{m} 1-\mathrm{m} 3$ en vistas oclusal $\mathrm{y}$ labial/ right mandibular fragment with incisive, canine and $m 1-m 3$ in occlusal and labial views; 4-5, Argyrolagoidea indet., MPEF-PV 4846, fragmento mandibular ?izquierdo con un molariforme/ ?left mandibular fragment with a molariform tooth. Escala/ scale $=1 \mathrm{~mm}$. ovalado, comprimido en sentido labiolingual y más estrecho posteriormente. El esmalte rodea totalmente al diente, pero la capa se adelgaza en la porción posterolabial y en la mayor parte de su cara lingual. La cara oclusal muestra una pendiente abrupta desde el extremo anterior al posterior; no obstante, está por encima del plano oclusal de la serie molar.

El ?canino inferior es procumbente, algo ovalado, con el eje menor orientado en sentido labiolingual.

Los molares inferiores son subcuadrangulares, siendo el m1 más largo que ancho y presentando un surco vertical muy superficial en la cara lingual; el m2 es más cuadrangular, con sus caras anterior y posterior planas; por último, el m3 es más triangular, con un vértice posterolingual saliente, las caras anterior y lingual planas, en un ángulo de $90^{\circ}$, y la cara labial curva uniendo las dos anteriores. Todos los molares presentan una faceta de desgaste de dirección anterolabial-posterolingual, evidenciando movimientos propalinales de masticación.

Entre los molares superiores, el M1 es subcuadrangular, con la cara anterior curva y la posterior bien plana. Presenta una implantación recumbente (hacia atrás). El M2, menos recumbente que el M1, es subcuadrangular con las caras laterales y posterior planas y la anterior curva. El M3 es subtriangular y de implantación vertical, con la cara anterior aplanada y las caras labial y lingual convergiendo hacia la parte posterior del diente. $\mathrm{Al}$ igual que los molares inferiores, los superiores presentan una faceta de desgaste con orientación posterolingual-anterolabial.

\section{Argyrolagoidea indet.}

\section{Figura 5.4-5}

Material referido. Fragmento mandibular ?izquierdo con un molariforme, MPEF-PV 4846.

Procedencia geográfica y estratigráfica. "Loma Blanca", Parque Paleontológico de Bryn Gwyn, sobre el margen sur del Río Chubut a la altura de Gaiman, provincia del Chubut, Argentina. Unidad ¿̇superior? del Miembro Trelew, Formación Sarmiento.

Medidas. Molariforme: largo, 1,1 mm; ancho, 0,8 mm.

Descripción y comentarios. El ejemplar es demasiado fragmentario como para precisar sus probables afinidades dentro de los Argyrolagoidea. En el extremo anterior se ha preservado parte del alvéolo de un incisivo hipertrofiado y procumbente. Posterior a éste, existe un alvéolo simple y subcircular. Por detrás, se observa una cresta muy corta que separa el último alvéolo del primer molariforme. Este diente es euhipsodonte, de contorno irregular y con dos surcos, uno lingual y otro labial, que lo dividen en dos lóbulos claramente asimétricos, de los 
cuales el posterior es más largo y ancho que el anterior. El molariforme presenta cierto desgaste; ambos surcos recorren toda la altura del diente hasta la base de la corona. La raíz es abierta.

Comparado con los argirolágidos y patagónidos conocidos, MPEF-PV 4846 muestra al menos un rasgo distintivo: el diastema extremadamente corto entre el primer molariforme y el alvéolo anterior. Además, el diastema no es plano, sino en forma de cresta. Los surcos del molariforme no son tan profundos como en los argirolágidos ni tan superficiales como en los patagónidos subadultos. En cuanto al contorno oclusal del molariforme, es suavemente bilobulado a diferencia de los patagónidos, mientras que, a diferencia de los argirolágidos, no termina en forma aguda, sino plana.

Posiblemente, este ejemplar constituya un nuevo taxón de Argyrolagoidea. A la espera de materiales más completos, optamos por considerarlo un Argyrolagoidea indet.
Cohorte “Ameridelphia” Szalay, 1982

Orden Didelphimorphia Gill, 1872

Superfamilia Didelphoidea Gray, 1821

Didelphoidea indet.

Figura 7

Material referido. Fragmento de maxilar izquierdo conservando parte de la región palatal, las raíces de los P1 y P3 y los P2 y M1-M4 completos, muy desgastados, MLP 77-VI13-26 (Fig. 7).

Procedencia geográfica y estratigráfica. Barranca Sur del lago Colhue Huapi (Departamento de Sarmiento, Provincia del Chubut, Argentina). Niveles inciertos, probablemente referibles al Miembro Colhue Huapi de la Formación Sarmiento (Edad mamífero Colhuehuapense) (H. Herrera, com. pers., 2005).

Medidas. P3: largo, 2,77 mm, ancho, $1 \mathrm{~mm}$; M1: largo,

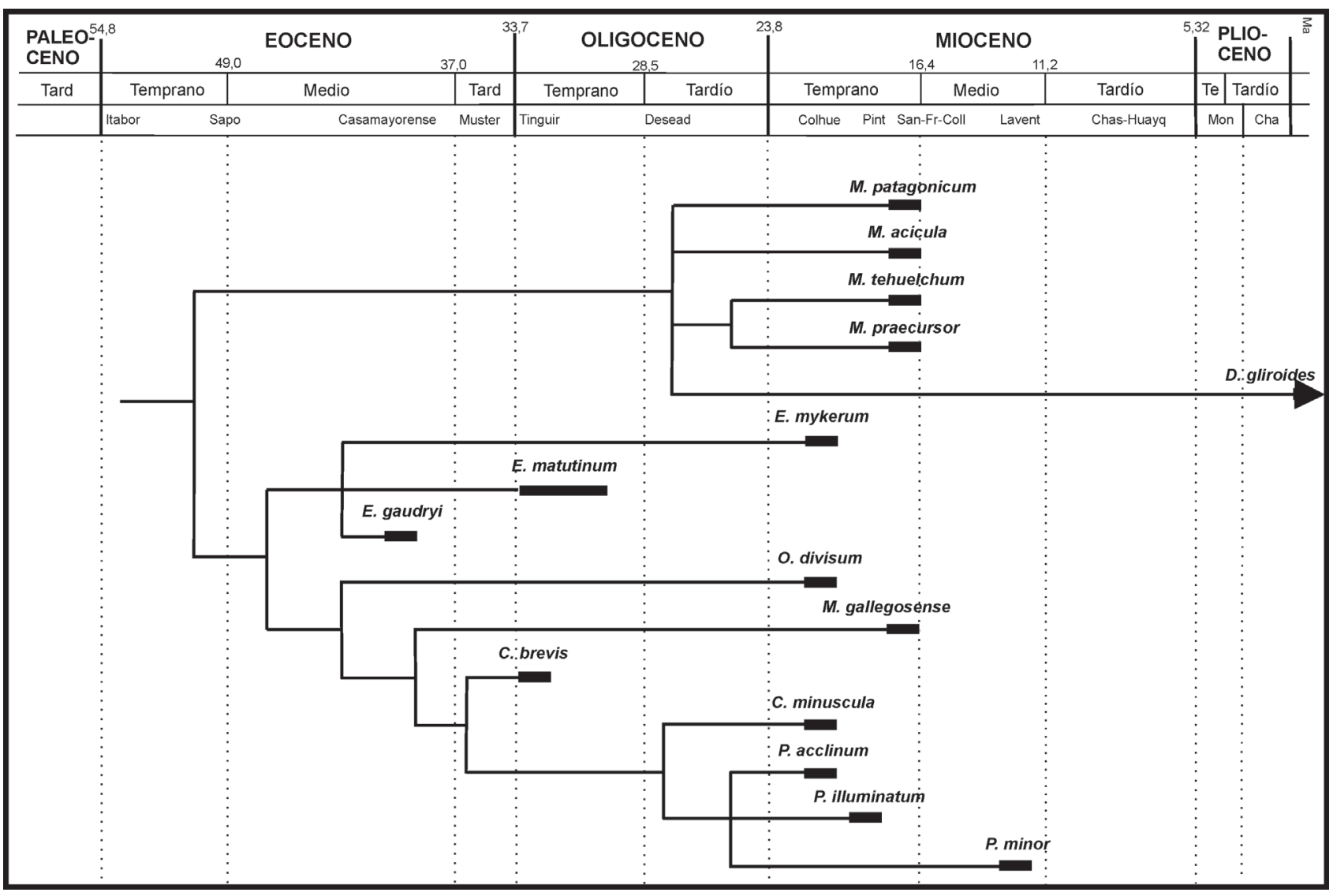

Figura 6. Filogenia de los Microbiotheriidae calibrada en el tiempo, basada en el cladograma de la Figura 2. Las barras sólidas indican las distribuciones temporales conocidas. Las unidades geocronológicas, Edades mamífero y faunas están basadas en Flynn and Swisher (1995) y Gelfo et al. (2009)/ time-calibrated phylogeny of Microbiotheriidae based on cladogram in Figure 2. Known ranges of species are indicated by solid bar. Geochronologic units, mammal Ages, and faunas based on Flynn and Swisher, 1995 and Gelfo et al., 2009. Itabor, Itaboraiense/ Itaboraian; Sapo, fauna de Paso del Sapo/ Paso del Sapo fauna; Muster, Mustersense/ Mustersan; Tinguir, Tinguiririquense/ Tinguirirican; Desead, Deseadense/ Deseadan; Colhue, Colhuehuapense/ Colhuehuapian; Pint, fauna Pinturense/ Pinturan Fauna; Sant-Fr-Coll, Santacrucense, Friasense y Colloncurense/ Santacrucian, Friasian, and Colloncuran; Lavent, Laventense/ Laventan; Chas-Huay, Chasiquense y Huayqueriense/ Chasicoan and Huayquerian; Mon, Montehermosense/ Montermosan; Cha, Chapadmalalense/ Chapadmalalan. 
3,71 mm, ancho, 3,40 mm; M2: largo, 3,84 mm; M3: largo, 3,77 mm; M4: largo, 3,25 mm, ancho, 3,61 mm.

Descripción. El maxilar ha preservado el borde labial y anterior del foramen palatino mayor del lado izquierdo; aparentemente, el extremo anterior de este foramen llegaba hasta el nivel de la raíz anterior del P3. Los premolares superiores son alargados y más bien comprimidos en sentido labiolingual. Existe un diastema notable entre el P1 y el P2. A juzgar por los alvéolos y las raíces de $\mathrm{P} 1$ y P3, la diferencia de tamaño entre el P1 y el P2 (este último, más grande), por un lado, y entre el P2 y el P3 (este último, más grande), por el otro, es relativamente abrupta. El P2 es tricúspide, con la cúspide central mucho más grande y alta que la anterior y la posterior. La cara labial de este diente es relativamente plana, mientras que la lingual es algo convexa. El diente está engrosado en su porción media, a la altura de la base y por encima del borde anterior de la raíz posterior. El M4 de este ejemplar no está reducido con respecto al M3. Los molares muestran, como rasgo saliente, una fuerte cuenca del trígono limitada lingualmente por el protocono muy robusto. Los M1-M3 tienen los protoconos fuertemente desgastados y, en el caso de los M2-M3, parcialmente rotos, por lo que no es posible advertir la presencia definida de un metacónulo. No existe paracónulo en ninguno de estos molares. El M4, mejor preservado que los anteriores, no tiene paracónulo ni metacónulo. A juzgar por sus bases respectivas, el metacono es más grande que el paracono en los M1-M3. En el M4, ambas cúspides son subiguales en tamaño y altura. Las postmetacristas son sucesivamente más cortas del M1 al M4, en relación con el tamaño relativo de cada diente, y se orientan cada vez más transversalmente respecto del eje dentario. La plataforma estilar es muy angosta, si bien ha preservado las cúspides estilares $\mathrm{StA}, \mathrm{StB}, \mathrm{StC}$ y $\mathrm{StD}$ en todos los molares excepto en el M4, en el que se ha preservado sólo la StA y la $\mathrm{StB}$; una minúscula cúspide labial al metacono en este diente podría corresponder a la StD. El paracono y la StB están claramente apareados en los M1-M2; a pesar del fuerte desgaste, puede apreciarse que ambas cúspides están más separadas en el M3, aunque menos en el M4. La preparacrista, tal como se aprecia en el M2, es vestigial y termina labialmente en un punto por delante de la StB. La StA se ubica en un punto más bajo que el resto de las cúspides estilares. La StB es la cúspide más grande en todos los molares. La $\mathrm{StC}$ es equidistante de $\mathrm{StB}$ y $\mathrm{StD}$ en los M1-M2, aparentemente más reducida y desplazada en el M3 e inexistente en el M4. La StD es más reducida, menos diferenciada y comprimida labiolingualmente que la $\mathrm{StB}$ y disminuye de tamaño hacia atrás en la serie molar; no obstante, es más alta y diferenciada que la StC en los M1-M3.
Debido al grado de desgaste, es imposible apreciar con claridad la centrocrista en los M1-M3. En el M4, la centrocrista forma, en vista oclusal, una estructura en $\mathrm{V}$.

Comentarios. Las cúspides estilares muestran un moderado desarrollo, excepto la $\mathrm{StB}$ que es proporcionalmente grande, lo cual permite descartar su pertenencia a los Microbiotheria. Tampoco es referible a ningún grupo de Sparassodonta, ya que no muestra ninguno de los rasgos derivados característicos de estos últimos: gran desarrollo de las postmetacristas, orientadas más paralelas al eje dentario que en el ejemplar MLP 77-VI-13-26; reducción de los protoconos; y centrocrista recta y muy corta, con el paracono y el metacono muy próximos entre sí. En los Polydolopimorphia y Paucituberculata, por su parte, el paracono y el metacono se aparean con las $\mathrm{StB}$ y $\mathrm{StD}$, respectivamente. Si bien en MLP 77-VI-13-26 la StB se ubica muy próxima al paracono, la $\mathrm{StD}$ se aleja progresivamente del metacono del M1 al M4. Si bien no es posible verificar la presencia o ausencia de cónulos en los M1-M3 de este ejemplar, en el M4 están ausentes, mientras que en todos los Polydolopimorphia y en casi todos los Paucituberculata están presentes y bien desarrollados. En todo caso, la morfología posterolabial del protocono no sugiere agrandamiento alguno del metacónulo en el ejemplar MLP 77-VI-13-26. El conjunto de rasgos señalados sugiere, por el contrario, la pertenencia de MLP 77-VI-13-26 a algún grupo de Didelphimorphia, aún indeterminado. Lamentablemente, el grado de desgaste de la mayor parte de los molares de este ejemplar impide precisar sus posibles afinidades.

Orden indet.

Familia Derorhynchidae Marshall, 1987

Género Coona Simpson, 1938

Type species. Coona pattersoni Simpson, 1938.

Coona gutierrezi (Del Corro, 1977) n. comb.

1977. Microbiotherium gutierrezi Del Corro, p. 32.

1982. Eomicrobiotherium gutierrezi Marshall, p. 60, fig. 27.

Holotipo. MACN-A 18228, fragmento mandibular izquierdo con las raíces del p1, p3, m2 y m4, y con los p2, m1 y $\mathrm{m} 3$ casi completos (el $\mathrm{m} 3$ tiene roto el trigónido). Colectado por Orlando Gutiérrez en Febrero de 1975. Fue numerado erróneamente por Marshall (1982) como MACN-A 18288.

Procedencia geográfica y estratigráfica. Localidad " $\mathrm{E}$ " en Schaeffer (1947: 3, fig. 1); Cañadón Hondo, Chubut, Argentina. Serie de bentonitas verdes (bird clay). Eoceno tardío (Subedad Barranquense, Edad mamífero Casamayorense). 
Medidas. Largo del p2, 1,4 mm; ancho del p2, 0,6 mm; largo del m1, 1,3 mm; ancho del m1 (talónido), 0,9 mm; largo del m3, ca. 1,05 mm; ancho del m3 (talónido), 0,7 mm.

Diagnosis enmendada. Tamaño $40 \%$ menor que el de $C$. pattersoni; paracónido proporcionalmente menos reducido; sin cíngulo posterior al talónido.

Emended diagnosis. Size $40 \%$ smaller than C. pattersoni; less reduced paraconid; postcingulum absent.

Comentarios. Entre los resultados de este trabajo, se destaca la reconsideración de la entidad y diversidad de los representantes del género Microbiotherium (Microbiotheriidae). Esto ha permitido la exclusión de varias especies previamente referidas a este género (véase más arriba). Es el caso de "Microbiotherium” gutierrezi que, además, no puede ser asignada a ningún representante de la Familia Microbiotheriidae ni del Orden Microbiotheria. Si bien no constituye una especie de la Edad Colhuehuapense (objetivo principal de esta contribución), se comenta aquí por ser un resultado directo de este trabajo.

El holotipo (único espécimen asignado) de Microbiotherium gutierrezi, del Casamayorense de Cañadón Hondo, fue revisado previamente por Marshall (1982). Este autor asignó la especie al género Eomicrobiotherium, considerándolo entonces un Didelphidae. En este mismo género y como especie tipo del mismo, incluyó a $E$. gaudryi; esta última especie había sido referida previamente a "?Coona" por Simpson (1964, p. 7). Posteriormente (Marshall, 1987; Marshall et al., 1990), se incluyó a Eomicrobiotherium entre los Microbiotheriidae.

Nuestra revisión del holotipo de E. gutierrezi (MACN-A 18288) nos lleva a la conclusión de que no pertenece a la Familia Microbiotheriidae. El material consiste en una man- díbula izquierda muy fragmentaria y cubierta por laca en la que se han preservado el $\mathrm{p}$ ?3, el $\mathrm{m} 1 \mathrm{y}$ parte del $\mathrm{m} 3$. El cuerpo mandibular es relativamente bajo y alargado. El p?3 es bajo, pero robusto, y su cúspide central se encuentra fuertemente inclinada hacia delante; se aprecia un amplio diastema entre este diente y el $\mathrm{m} 1$; la raíz anterior aparenta estar menos desarrollada que la posterior. El m1 tiene el trigónido más largo que el talónido; el protocónido es subigual en altura al metacónido; el paracónido es mucho más bajo que las dos primeras cúspides, la paracrístida está bien desarrollada; el talónido es muy corto; el entocónido es robusto, mucho más alto que el hipocónido, y ocupa buena parte de la pared lingual; no se aprecia desarrollo alguno de la pre-entocrístida; el hipocónido es más saliente labialmente que el protocónido; la crístida oblicua termina anteriormente en un punto por debajo de la porción central de la pared posterior del protocónido; el hipoconúlido está notablemente reducido y se ubica inmediatamente por detrás del entocónido; no hay cíngulo posterior al talónido; finalmente, el cíngulo anterobasal está moderadamente desarrollado y bien extendido desde la base del paracónido hasta la base del protocónido. El m3 está roto a nivel del trigónido; su tamaño es subigual o apenas mayor que el del m1; el resto de su morfología no presenta mayores diferencias con aquél. A juzgar por los alvéolos del $\mathrm{m} 4$, este molar era subigual o apenas menor que el m3; la raíz posterior del m4 es más chica que la anterior, lo que sugiere que el talónido estaba algo reducido.

El ejemplar MACN-A 18288 pertenece en realidad a los "Ameridelphia" Derorhynchidae. La paracrístida bien desarrollada, el acortamiento del talónido, la reducción del hipoconúlido y el gran tamaño y la forma columnar del entocónido son rasgos derivados que excluyen a "M." gutierrezi de

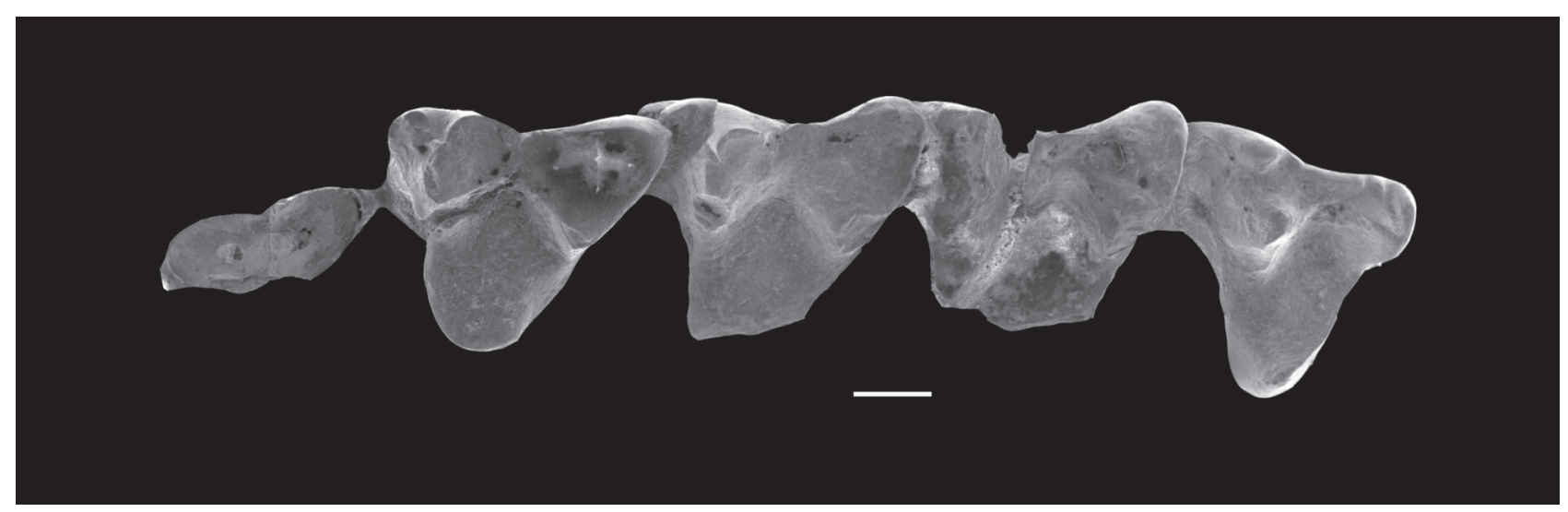

Figura 7. Didelphoidea indet. MLP 77-VI-13-26, fragmento maxilar izquierdo con las raíces de los P1 y P3 y los P2 y M1-M4 completos, en vista oclusal/ left maxillary fragment with $P 1$ and $P 3$ roots, and complete $P 2$ and $M 1-M 4$, occlusal view. Escala/ scale $=1 \mathrm{~mm}$. 
los Microbiotheriidae. Adicionalmente, la no reducción del m4 y de los cíngulos anterobasales de los molares inferiores constituye un rasgo plesiomorfo ausente en los microbiotéridos y presente en los derorrínquidos, al igual que todos los rasgos derivados mencionados en primer término (Goin, 1991; Goin et al., 1996).

En el contexto de los Derorhynchidae, MACN-A 18228 muestra mayores afinidades con Coona pattersoni, especie de la misma edad y de la cual se distingue por su tamaño claramente menor y la ausencia de cíngulo posterior al talónido (postcrístida); asimismo, el paracónido está menos reducido y menos comprimido anteroposteriormente. Por todos estos argumentos, referimos la especie $M$. gutierrezi al Género Coona (Derorhynchidae), dando lugar a la nueva combinación Coona gutierrezi.

\section{CONCLUSIONES}

\section{Microbiotheria}

El análisis cladístico de los Microbiotheriidae es el primero realizado desde el esquema de relaciones filogenéticas propuesto por Marshall (1982). Nuestros resultados difieren de la hipótesis presentada por este autor en que Oligobiotherium divisum y "Microbiotherium" gallegosense conforman un clado distinto del que agrupa a $M$. acicula, $M$. patagonicum, $M$. tehuelchum y D. gliroides. Otro resultado contrastante es la pertenencia de los clados Eomicrobiotherium y Pachybiotherium a los Microbiotheriidae.

La composición taxonómica actual de los Microbiotheriidae difiere de la considerada por Marshall (1982) en el reconocimiento de las especies Clenia minuscula y Oligobiotherium divisum y en la inclusión de Eomicrobiotherium gaudryi y Pachybiotherium acclinum, excluyéndolas de Didelphidae, así como de otras especies reconocidas recientemente (Goin 1997, Goin et al., 2010a, Goin et al., 2010b). Asimismo, en este trabajo se justifica la exclusión de Coona gutierrezi n. comb. (Microbiotherium gutierrezi, sensu Del Corro 1977) de los Microbiotheriidae, un taxón que había sido incluido en Eomicrobiotherium por Marshall (1982).

Para Marshall (1982), la máxima diversificación taxonómica de los microbiotéridos habría ocurrido en el Santacrucense, con el registro de cuatro especies pertenecientes al género Microbiotherium. Por el contrario y como resultado de esta revisión, se aprecia que la máxima diversidad ocurrió en el Colhuehuapense, con el registro de cinco géneros y cinco especies (una de ellas innominada; Tabla 3). En el nuevo esquema taxonómico, en el Santacrucense están presentes cinco especies, pero pertenecientes a sólo dos géneros.
Si bien existen incertezas en las relaciones filogenéticas de los microbiotéridos, expresadas en dos politomías en la filogenia obtenida (Fig. 2), es posible especular acerca de las principales etapas de diversificación evolutiva de estos metaterios. Puesta en un contexto temporal (Fig. 6), la filogenia de los microbiotéridos muestra que es probable que este grupo haya tenido dos cladogénesis principales. La primera, a principios o mediados del Eoceno, dando origen a los dos clados mayores de microbiotéridos: el que agrupa a Microbiotherium y Dromiciops, por un lado, y el que agrupa los restantes microbiotéridos, por el otro. La segunda, a fines del Oligoceno o principios del Mioceno, produciendo la diversificación de los clados Clenia-Pachybiotherium y Microbiotherium-Dromiciops. Estos dos eventos no agotan las radiaciones ocurridas entre los miembros del orden: los Woodburnodontidae más antiguos conocidos (los miembros más generalizados del orden) corresponden al Paleoceno tardío-Eoceno temprano de la Formación Las Flores (Goin y Forasiepi, datos no publicados), por lo que es posible hipotetizar un origen y una radiación inicial de los Microbiotheria en el Paleoceno (¿medio?).

\section{Polydolopimorphia}

La presencia de Proargyrolagus entre los marsupiales colhuehuapenses de la Patagonia constituye un hallazgo interesante e inesperado. Al igual que en el caso de Necrolestes Ameghino, 1891 (Goin et al., 2007a), dicho registro parece ser, más probablemente, fruto directo de la gran presión de muestreo que se ha venido realizando en niveles del Miembro Colhue-Huapi de la Formación Sarmiento. Es así que taxones usualmente poco o nada representados por causas diversas (tafonómicas, bajo número poblacional, etc.) aparecen en el registro, aumentando así nuestro conocimiento de la diversidad de la fauna de esta edad. Hasta ahora, Proargyrolagus era conocido sólo por su especie tipo, P. boliviensis, procedente de niveles deseadenses de la localidad de Salla, Bolivia. Por lo tanto, el registro de $P$. argentinus sp. nov. amplía las distribuciones temporal y geográfica previamente conocidas para este género.

Anargyrolagus primus y Patagonia peregrina estaban representadas por restos fragmentarios de sus denticiones. El conjunto de especímenes aquí estudiados incluyó ejemplares con la dentición inferior completa de $A$. primus y la superior de $P$. peregrina, permitiendo de este modo incrementar el conocimiento de sus series dentarias y la morfología molar. Asimismo, el estudio de la morfología dentaria de $A$. primus y $P$. argentinus fue clave para la comprensión de las homologías de cúspides y crestas de los Argirolagidae neógenos más derivados. 


\section{AGRADECIMIENTOS}

Agradecemos a M.G. Vucetich y a C. Deschamps por toda la ayuda recibida en torno a los especímenes recolectados en el campo. Al personal del MLP, MACN, UBA y Duke (técnicos, estudiantes, investigadores y responsables del proyecto) que colectó y/o revisó los concentrados fosilíferos de los cuales proceden muchos de los especímenes estudiados. A M. Tomeo por la confección de las figuras que ilustran este trabajo. A un revisor anónimo, A. Forasiepi y E. Cerdeńo por sus valiosas observaciones y comentarios al manuscrito originalmente enviado. F. Goin agradece a la Fundación Alexander von Humboldt (Alemania). F. Goin y A. Abello agradecen al CONICET (Argentina, PIPs 5621 y 0361). Parte sustancial de los materiales aquí estudiados fueron colectados merced a un subsidio de la National Science Foundation (Grants SBR 93-18942 y DEB 99-07985) a R. Kay, R. Madden (Duke University) y colegas del MLP.

\section{BIBLIOGRAFÍA}

Ameghino, F. 1887. Enumeración sistemática de las especies de mamíferos fósiles coleccionados por Carlos Ameghino en los terrenos eocenos de la Patagonia austral. Boletín del Museo de La Plata 1: 1-26.

Ameghino, F. 1889. Contribución al conocimiento de los mamíferos fósiles de la República Argentina. Actas de la Academia Nacional de Ciencias de Córdoba 6: 1-1027.

Ameghino, F. 1891. Mamíferos y aves fósiles argentinas. Especies nuevas, adiciones y correcciones. Revista Argentina de Historia Natural 1: 240-259.

Ameghino, F. 1898. Sinopsis geológico-paleontológica. Segundo Censo Nacional de la República Argentina 1: 111-255.

Ameghino, F. 1901. Notices préliminaires sur des ongulés nouveaux des terrains Crétacés de Patagonie. Boletin de la Academia Nacional de Ciencias de Córdoba 16: 349-426.

Ameghino, F. 1902. Première contribution a la connaissance de la faune mammalogique des couches à Colpodon. Boletín de la Academia Nacional de Ciencias de Córdoba 17: 71-138.

Ameghino, F. 1903-1904. Nuevas especies de mamíferos cretáceos y terciarios de la República Argentina. Anales de la Sociedad Científica Argentina 56: 193-208 (1903); 57:162-175, 327-341; 58: 35-71, 182-192, 225-291 (1904).

Ameghino, F. 1906. Les formations sédimentaires du Cretácé supérieur et du Tertiaire de Patagonie avec un parallèle entre leurs faunes mammalogiques et celles de l'ancien continent. Anales del Museo Nacional Historia Natural de Buenos Aires 15: 1-568.

Ameghino, F. 1907. El origen del hombre. La Reforma, La Plata, p. 256-265.

Archer, M. 1984. The Australian marsupial radiation. En: Archer y G. Clayton (Eds.), Vertebrate zoogeography and evolution in Australasia. Hesperian Press, Perth, p. 633- 808.

Carlini A.A., Pascual R., Goin F.J. 2007. A new argyrolagid marsupial from the Early Miocene of Patagonia (Argentina). Neues Jahrbuch für Geologie und Paläontologie 245: 323-330.

Del Corro, G. 1977. Un nuevo microbiotherio (Marsupialia) del Eoceno de Patagonia. Revista del Museo Argentino de Ciencias Naturales "Bernardino Rivadavia" 2: 31-3

Eaton, J.G. 1993. Therian mammals of the Cenomanian (Late Cretaceous) Dakota Formation, southwestern Utah. Journal of Vertebrate Paleontology 13: 105-124.

Flynn, J. y Swisher, C.C. III 1995. Cenozoic South American Land Mammal Ages: Correlation to global geochronologies. En: W.A. Berggren, D.V. Kent, M.P. Aubry y J. Hardenbol (Eds.), Geochronology, time scales, and global stratigraphic correlation. SEPM (Society for Sedimentary Geology) Special Publication 54: 317-333.

Gelfo, J.N., Goin F.J., Woodburne, M.O. y de Muizon, C. 2009. Biochronological relationships of the earliest South American Paleogene mammalian faunas. Palacontology 52: 251-269.

Gill, T. 1872. Arrangement of the families of mammals with analytical tables. Smithsonian Miscellaneous Collections 11: 1- 22.
Goin, F.J. 1991. [Los Didelphoidea (Mammalia, Marsupialia, Didelphimorphia) del Cenozoico tardío de la Región Pampeana. Tesis doctoral. Universidad Nacional de La Plata, La Plata, Argentina, 327 p. Inédita].

Goin, F.J. 1997. New clues for understanding Neogene marsupial radiations. En: R F. Kay, R.H. Madden, R.L. Cifelli y J.J. Flynn (Eds.), $A$ History of the Neotropical Fauna. Vertebrate Paleobiology of the Miocene in Colombia. Smithsonian Institution Press, Washington, p. 185-204.

Goin, F.J. 2006. A review of the Caroloameghiniidae, Paleogene South American "primate-like" marsupials (?Didelphimorphia, Peradectoidea). En: D. Kalthoff, T. Martin y T. Möors (Eds.), Festband für Herrn Professor Wighart v. Koenigswald anlässlich seines 65, Geburtstages. Palaeontographica Abteilung A 278: 57-67.

Goin, FJ. y Candela, A. 2004. New Paleogene marsupials from the Amazon Basin of Eastern Perú. En: K.E. Campbell Jr. (Ed.), The Paleogene mammalian fauna of Santa Rosa, Amazonian Perú. Natural History Museum of Los Angeles County, Sciences Series 40: 15-60.

Goin, F.J., Candela, A.M.; Bond, M., Pascual, R. y Escribano, V. 1996. Una nueva "comadreja" (Mammalia, Marsupialia) del Paleoceno de Patagonia. Congreso Paleógeno de América del Sur (Santa Rosa), Resúmenes, p. 12.

Goin, F.J., Woodburne, M.O., Case, J.A., Vizcaíno, S.F. y Reguero, M. 1999. New discoveries of "opossum-like" marsupials from Antarctica (Seymour Island, Middle Eocene). Journal of Mammalian Evolution 6: 335-365.

Goin, F.J., Sánchez-Villagra, M.R., Kay, R.F., Anaya- Daza, F. y Takai, M. 2003. New palaeothentid marsupial from the Middle Miocene of Bolivia. Palaeontology 46: 307-315.

Goin, F.J., Abello A., Bellosi, E., Kay, R., Madden, R. y Carlini, A.A. 2007a. Los Metatheria sudamericanos de comienzos del Neógeno (Mioceno temprano, Edad-mamífero Colhuehuapense). Parte I: Introducción, Didelphimorphia y Sparassodonta. Ameghiniana 44: 29-71.

Goin, F.J., Zimicz, N., Reguero, M.A., Santillana, S., Marenssi, S.A. y Moly, J.J. 2007b. New Mammal from the Eocene of Antarctica, and the origins of the Microbiotheria. Revista de la Asociación Geológica Argentina 62: 597-603.

Goin, F.J., Abello, M.A. y Chornogubsky, L. 2010a. Middle Tertiary marsupials from central Patagonia (early Oligocene of Gran Barranca): understanding South America's Grande Coupure. En: R.H. Madden, A.A., Carlini, M.G. Vucetich y R.F. Kay (Eds.), The Paleontology of Gran Barranca: Evolution and Environmental Change through the Middle Cenozoic of Patagonia. Cambridge University Press, Cambridge, p. 71-107.

Goin F.J., Tejedor, M.F., Abello, M.A., Martin, G. M. 2010b. Un nuevo microbiotérido (Mammalia, Marsupialia, Microbiotheria) de la Formación Pinturas (Mioceno temprano) de la provincia de Santa Cruz. Ameghiniana 47: 117-122.

Goin, FJ., Zimicz, N., Forasiepi, A.M., Chornogubsky, L.C., Abello, M.A. En prensa. The Rise and Fall of South American Metatherians: Contexts, Adaptations, Radiations, and Extinctions. En: A.L. Rosenberger y M.F. Tejedor (Eds.), Origins and Evolution of Cenozoic South American Mammals. Springer.

Goloboff, P.A y Farris, J.S. 2001. Methods for quick consensus estimation. Cladistics 17: 26-34.

Goloboff, P.A., Farris, J. y Nixon, K. 2003. T.N.T.: tree analysis using new technology. Program and documentation available from the authors and at: http://www.zmuc.dk/public/ phylogeny.

Gray, J.E. 1821. On the natural arrangement of vertebrose animals. London Medical Repository, Monthly Journal and Review 15: 296-311.

Hershkovitz, P. 1971. Basic crown pattern and cusp homologies of mammalian teeth. En A.A. Dahlberg (Ed.), Dental morphology and evolution. University Chicago Press, Chicago, p. 95-150.

Hershkovitz, P. 1982. The staggered marsupial lower third incisor (I3). Geobios, Mémoire Special 6: 191-200.

Hoffstetter, R. y Villarroel, C. 1974. Découverte d'un marsupial microtagulidé (Argyrolagidé) dans le Pliocène de l'Altiplano bolivien. Comptes Rendus de l'Académie des Sciences, Paris 278: 1947-1950.

Huxley, T.H. 1880. On the applications of the laws of evolution to the arrangement of the Vertebrata and more particulary of the Mammalia. Proceedings of the Zoological Society of London 1880: 649-66. 
Marshall, L.G. 1978. Evolution of the Borhyaenidae, extinct South American predaceous marsupials. University of California Publications in Geological Sciences 117: 1-89.

Marshall, L.G. 1982. Systematics of the South American marsupial family Microbiotheriidae. Fieldiana, Geology 10: 1-75.

Marshall, L.G. 1987. Systematics of Itaboraian (Middle Paleocene) age "opossum-like" marsupials from the limestone quarry at São José de Itaboraí, Brazil. En: M. Archer (Ed.), Possums and Opossums, Studies in Evolution, Vol 1. Surrey Beatty and Sons, Sydney, p. 91-160.

Marshall, L.G. y Muizon, C. de 1995. Part II: The skull. En: Pucadelphys andinus (Marsupialia, Mammalia) from the early Palaeocene of Bolivia. Mémoires du Muséum national d'Histoire naturelle 165: 21-90.

Marshall, L.G., Case, J.A., Woodburne, M.O. 1990. Phylogenetic relationships of the families of marsupials. Current Mammalogy 2: 433-502.

Mones, A. 1982. An equivocal nomenclature: what means hypsodonty? Paläontologisches Zeitschrift 56: 107-111.

Oliveira, E.V. 1998. [Taxonomia, filogenia e paleobiogeografia de marsupiais "poliprotodontes" do Mesopaleoceno da Bacia de Itaborai, Rio de Janeiro, Brasil. Tesis doctoral. Universidad Federal de Rio Grande do Sul, 327 p. Inédita].

Oliveira, E.V. y Goin, F.J. 2011. A reassesment of bunodont metatherians from the Paleogene of Itaboraí (Brazil): Systematics and age of the Itaboraian SALMA. Revista Brasileira de Paleontologia 14: 105-136.

Pascual, R. 1980. Nuevos y singulares tipos ecológicos de marsupiales extinguidos de América del Sur (Paleoceno tardío o Eoceno temprano) del Noroeste argentino. 20 Congreso Argentino de Paleontología y Bioestratigrafia y $10^{\circ}$ Congreso Latinoamericano de Paleontología (Buenos Aires), Actas 2: 151-173.

Pascual, R. y Carlini, A.A. 1987. A new superfamily in the extensive radiation of South American Paleogene marsupials. Fieldiana Zoology, new series 39: 99-110.

Pascual, R., y Odreman Rivas, O. 1971. Evolución de las comunidades de los vertebrados del Terciario argentino. Los aspectos paleozoogeográficos y paleoclimáticos relacionados. Ameghiniana 8: 372-412.

Paula Couto, C. de 1952. Fossil mammals from the begining of the Cenozoic in Brazil. Marsupialia: Didelphidae. American Museum Novitates 1567: 1-26.

Reig, O.A. 1955. Noticia preliminar sobre la presencia de microbiotherinos vivientes en la fauna Sudamericana. Investigaciones Zoológicas Chilenas 2: $121-30$

Reig, O.A., Kirsch, J.A .W. y Marshall, L.G. 1987. Systematic relationships of the living and neocenozoic American "opossum-like" marsupials (suborder Didelphimorphia), with comments on the classification of these and of the Cretaceous and Paleocene New World and European metatherians. En: M. Archer (Ed.), Possums and Opossums-Studies in Evolution, Vol 1. Surrey Beatty and Sons, Sydney, p. 1-89.

Rieppel, O. 1988. Fundamentals of Comparative Biology. Birkhäuser Verlag, Basilea, $202 \mathrm{p}$.

Rieppel, O. 1994. Homology, topology, and typology: the history of modern debates. En: B.K. Hall (Ed.), Homology: The Hierarchical Basis of Comparative Biology. Academic Press, NuevaYork, p. 63-100.
Ringuelet, A.B. 1953. Revisión de los didelfidos fósiles argentinos. Revista del Museo Universidad Eva Perón 3: 265-308.

Sánchez-Villagra, M.R. y Kay, R.F. 1997. A skull of Proargyrolagus, the oldest argyrolagid (Late Oligocene Salla Beds, Bolivia), with brief comments concerning its paleobiology. Journal of Vertebrate Paleontology 17: 717-724.

Sánchez-Villagra, M.R, Kay, R.F. y Anaya-Daza, F. 2000. Cranial anatomy and paleobiology of the Miocene marsupial Hondalagus altiplanensis and a phylogeny of argyrolagids. Palaeontology 43: 287-301.

Schaeffer, B. 1947. An Eocene serranid from Patagonia. American Museum Novitates 1331:1-9.

Simpson, G.G. 1930. Post- Mesozoic Marsupialia. En: J.F. Pompeckj (Ed.), Fossilium Catalogus I: Animalia, pars 47. Backhuys, Berlín, p. 1-87.

Simpson, G.G. 1932. Some new or little-known marsupials from the Colpodon beds of Patagonia. American Museum Novitates 575: 1-12.

Simpson, G.G. 1938. A new marsupial from the Eocene of Patagonia. American Museum Novitates 989: 1-5.

Simpson, G.G. 1964. Los mamíferos casamayorenses de la Colección Tournouër. Revista del Museo Argentino de Ciencias Naturales 1: 1-21.

Simpson, G.G. 1967. The beginning of the age of mammals in South America. Part. 2. Bulletin of the American Museum of Natural History 137: 1-259.

Simpson, G.G. 1970. The Argyrolagidae, extinct South American marsupials. Bulletin of the Museum of Comparative Zoology 139: 1-86.

Szalay, F.S. 1982. A new appraisal of marsupial phylogeny and classification. En: M. Archer (Ed.), Carnivorous Marsupials, Vol. 2. Royal Zoological Society of New South Wales, Sydney, p. 621-640.

Thomas, O. 1894. On Micoureus griseus, Desm., with description of a new genus and species of Didelphidae. Annals and Magazine of Natural History 6:184-188.

Vucetich, M.G., Kramarz, A.G. y Candela, A.M. 2010. Colhuehuapian rodents from Gran Barranca and other Patagonian localities: the state of the art. En: R.H. Madden, A.A. Carlini, M.G. Vucetich y R.F. Kay (Eds.), The Paleontology of Gran Barranca: Evolution and Environmental Change through the Middle Cenozoic of Patagonia. Cambridge University Press, Nueva York, p. 206-220.

Vullo, R., Gheerbrant, E., Muizon, C. de y Néraudeau, D. 2009. The oldest modern therian mammal from Europe and its bearing on stem marsupial paleobiogeography. Proceedings of the National Academy of Sciences 106: 19910-19915.

Wolff, R.G. 1984. A new Early Oligocene Argyrolagoid (Mammalia, Marsupialia) from Salla, Bolivia. Journal Vertebrate Paleontology 4: 108-113.

doi: 10.5710/AMGH.9.11.2012.570

Recibido: 11 de enero de 2012

Aceptado: 9 de noviembre de 2012 